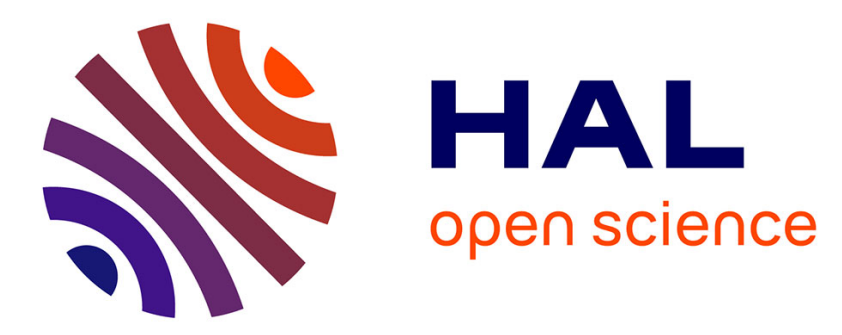

\title{
Radiocatalytic Cu-incorporated TiO 2 nano-particles for the degradation of organic species under gamma irradiation
}

L. Samet, K. March, O. Stephan, N. Brun, F. Hosni, F. Bessousa, J. Benasseur, R. Chtourou

\section{To cite this version:}

L. Samet, K. March, O. Stephan, N. Brun, F. Hosni, et al.. Radiocatalytic Cu-incorporated TiO 2 nano-particles for the degradation of organic species under gamma irradiation. Journal of Alloys and Compounds, 2018, 743, pp.175-186. 10.1016/j.jallcom.2018.02.001 . hal-02335602

\section{HAL Id: hal-02335602 https://hal.science/hal-02335602}

Submitted on 28 Oct 2019

HAL is a multi-disciplinary open access archive for the deposit and dissemination of scientific research documents, whether they are published or not. The documents may come from teaching and research institutions in France or abroad, or from public or private research centers.
L'archive ouverte pluridisciplinaire HAL, est destinée au dépôt et à la diffusion de documents scientifiques de niveau recherche, publiés ou non, émanant des établissements d'enseignement et de recherche français ou étrangers, des laboratoires publics ou privés. 


\title{
Radiocatalytic $\mathrm{Cu}$-incorporated $\mathrm{TiO}_{2}$ nano-particles for the degradation of organic species under gamma irradiation
}

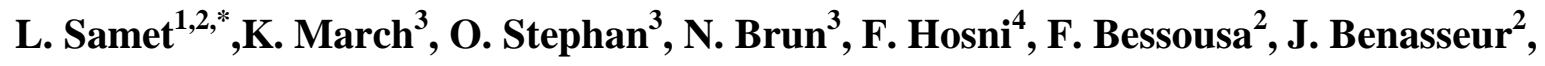 \\ R. Chtourou ${ }^{2}$
}

${ }^{1}$ Institut Préparatoire aux Etudes d'Ingénieurs d'El-Manar, Université Tunis El Manar, Campus Universitaire Farhat Hached d'El-Manar 2092 El Manar, Tunis, Tunisia.

${ }^{2}$ Laboratoire de Nanomatériaux et Systèmes pour les Energies Renouvelables, Centre de Recherches et des Technologies de l'Energie, Technopole Borj Cedria, Bp 95, hammammlif 2050, Tunisia.

${ }^{3}$ Laboratoire de Physique des Solides, UMR 8502 CNRS - Université Paris-Sud, Bât 510, 91405

Orsay cedex France.

${ }^{4}$ Laboratoire de Recherche en Energie et Matière pour le Développement des Sciences Nucléaires, Centre National des Sciences et Technologie Nucléaires, 2020 Sidi-Thabet, Tunisia.

*Corresponding author:lolwa.samet@ipeiem.utm.tn

\begin{abstract}
We report on an experimental study aimed at optimizing the radiocatalytic properties of pure and copper-incorporated $\mathrm{TiO}_{2}$ powders. This has been achieved by conducting crosschecked structural, optical and radiocatalytic studies. Structural and nanoscale analyses show evidence of internal doping by $\mathrm{Cu}^{2+}$ in the $\mathrm{TiO}_{2}$ lattice that leads to the reduction of the optical band gap down to $1.5 \mathrm{eV}$. The effect of gamma radiation on the radiocatalytic activity of these catalysts was studied by degradation of methylene blue as a model pollutant. It was found that the addition of $\mathrm{Cu}$-doped $\mathrm{TiO}_{2}$ (anatase) powders improves significantly the pollutant degradation, as compared to photocatalysis. The doping and the annealing temperature's impact on the structural, optical and radiocatalytic efficiencies are highlighted and correlated.
\end{abstract}

Keywords: Copper-doped titania, Structure, Optical and radiocatalytic relationship, ELNES. 


\section{Introduction}

Water is a scarce resource and wastewater is a major environmental problem. Advanced oxidation processes, like photocatalysis and radiocatalysis, are widely studied for the treatment of persistent organic compounds. Among several semiconductors used as heterogeneous photocatalysts and radiocatalysts, titanium dioxide $\left(\mathrm{TiO}_{2}\right)$ is the most widely used and has been intensively studied thanks to its many promising properties [1-37]. It presents a high chemical and mechanical stability and is amongst the synthetic nanoparticles that present especially interesting properties in the fields of nanotechnology, sustainable development and ecology. Titanium dioxide is a semiconductor that can only be activated with light of energy higher than about $3.2 \mathrm{eV}$ or $3.0 \mathrm{eV}$ for the anatase and rutile structures respectively. When $\mathrm{TiO}_{2}$ is subjected to illumination, the electron-hole pairs formed can be trapped by surface hydroxyl groups. In the presence of oxygen and water, the trapped carriers form free radicals that are strong oxidizing species and are likely to mineralize organic pollutants. In this respect, the efficiency of $\mathrm{TiO}_{2}$ catalysis needs to be further improved. Many strategies, such as doping [5-18], co-doping [20, 21], surface treatment [22], coupling with noble metal nanoparticles [23] or other semiconductors [24, 25], synthesis of nanomaterials with different morphologies [26], have been tried over the last few decades, in order to reduce the electron-hole recombination rate and improve the photocatalytic efficiency of $\mathrm{TiO}_{2}$. Titanium dioxide has a high oxidation power so is easily doped with active ions. It has been shown that doping with transition metal cations is an efficient way of promoting the photocatalytic activity [16-18]. Such doping can extend the light absorption range from the UV down to the visible by inducing additional energy levels within the band gap, leading to the improvement of the $\mathrm{TiO}_{2}$ photo-response. Several investigations on doped $\mathrm{TiO}_{2}$ have succeeded in providing some indication about the substitutional or interstitial dopant location and its impact on the physical and electronic structure of $\mathrm{TiO}_{2}[27,28]$. Doping with copper 
appears to be a particularly promising approach for photocatalytic applications [18]. For example, it has been found that the incorporation of $\mathrm{Cu}^{2+}$ ions into a $\mathrm{TiO}_{2}$ matrix can substitute for $\mathrm{Ti}^{4+}$ and/or segregate to the surface of $\mathrm{TiO}_{2}$ crystallites in the form of $\mathrm{CuO}$, $\mathrm{Cu}_{2} \mathrm{O}$ or metallic $\mathrm{Cu}[14,29-32]$ and improve significantly the photocatalytic activity. Theoretical investigations show that $\mathrm{Cu}$ doping can effectively narrow the band gap by creating impurity bands $[15,21]$, and thus improve the absorption of visible light in photocatalytic reactions. Alternatively, $\mathrm{Wu}$ and al. [33] reported that the dissolution of $\mathrm{Cu}$ ions in the $\mathrm{TiO}_{2}$ lattice leads to a reduction in photocatalytic activity. It is now admitted that a compromise must be achieved between the band gap value and charge transfer at the surface of $\mathrm{TiO}_{2}$ catalysts. However, the nature of the active copper species $\left(\mathrm{CuO}, \mathrm{Cu}_{2} \mathrm{O}\right.$, metallic $\mathrm{Cu}$, or isolated $\mathrm{Cu}^{2+}$ ions incorporated into the $\mathrm{TiO}_{2}$ lattice) and the factors that govern the $\mathrm{Cu}$ doped $\mathrm{TiO}_{2}$ photo-reactivity are still under debate. Also, there is a need to develop treatment methods that are more effective in eliminating dyes from waste streams. Ionizing radiation is known to degrade numerous pollutants. As in the case of photocatalysis, some publications reported that the addition of nanoparticles such as $\mathrm{TiO}_{2}$ and $\mathrm{AlO}_{2}$ in solution enhances the degradation of pollutants and accelerates the reaction induced by ionizing radiations [34-37]. However, the effect of doping on radiocatalysis has not been reported.

This work explores the local chemical environment of $\mathrm{Cu}$ dopants in the core and the near-surface regions of $\mathrm{TiO}_{2}$ nanoparticles prepared by a simple sol-gel route and annealed at $400^{\circ} \mathrm{C}$ or $600^{\circ} \mathrm{C}$. The characterization studies were conducted using various investigation techniques, including ultraviolet-visible spectroscopy (UV-vis), X-ray diffraction (XRD), transmission electron microscopy (TEM), electron energy-loss spectroscopy (EELS) and electron paramagnetic resonance (EPR) spectroscopy. Methylene blue (MB) was selected as a model compound for evaluating the potential of doped and undoped $\mathrm{TiO}_{2}$ to remove dyes from wastewater. By investigating the effect of the copper doping level and heat treatment on 
the structural and optical properties of a series of $\mathrm{TiO}_{2}$ catalysts and subsequently on their $\mathrm{MB}$ degradation efficiency under gamma illumination, we show that the performance of such systems strikingly depends on the nature and distribution of the $\mathrm{Cu}$ species incorporated.

\section{Experimental details}

Pure and $\mathrm{Cu}^{2+}$-doped $\mathrm{TiO}_{2}$ powders $\left(\mathrm{Cu}-\mathrm{TiO}_{2}\right)$ were prepared via a sol-gel technique. Details are presented in our previous work [6]. This method produces powders of high chemical purity. In this case the measured atomic ratio of $\mathrm{Cu}$ to $\mathrm{Ti}$ is between 0 and 12 at.\%. Undoped $\mathrm{TiO}_{2}$ samples were prepared as a controlin the same way. The obtained millimetric solids were ground in an agate mortar to get fine nanopowders. The nanopowders were systematically characterized after heat treatment at $400^{\circ} \mathrm{C}$ or $600^{\circ} \mathrm{C}$ in order to optimize their synthesis. In this regard, XRD, TEM and EELS are suitable characterization techniques as they allow one to identify the structures of crystallized phases and to observe possible structural changes after doping and heat treatment.

The X-ray diffractometer used was a Siemens D5005 in Bragg-Brentano geometry, furnishing $\mathrm{CuK} \alpha$ radiation $(\lambda=1.5406 \AA)$. The diffractograms were recorded at room temperature and the X-ray data were collected from $20^{\circ}$ to $80^{\circ}(2 \theta)$, with a measurement time of 10 seconds and a step size of $0.02^{\circ}(2 \theta)$.

TEM (TOPCON 002B at $100 \mathrm{keV}$ ) was used to study the morphology and the crystallographic structure of the powders, and their possible changes after heat treatment and doping. Nanopowders were dispersed in ethanol before drop casting a very dilute suspension on a carbon-film copper grid.

The electronic structure of $\mathrm{Cu}-\mathrm{TiO}_{2}$ powders was investigated by means of EELS performed in two dedicated scanning transmission electron microscopes (STEM), a probe $\mathrm{C}_{\mathrm{s}^{-}}$ corrected Nion Ultra-STEM and a STEM-VG HB501, both equipped with a field emission source operated at $100 \mathrm{keV}$ and coupled to a Gatan EELS spectrometer optically coupled to a 
high-sensitivity (either nitrogen-cooled or electron amplifying) CCD camera. EELS does not only perform elemental analysis of $\mathrm{Cu}$ inserted into the $\mathrm{TiO}_{2}$ structure after doping, it also provides information related to the local electronic structure of the materials (valence state of each element for example) with a high spatial resolution (down to the atomic scale).

For EPR analysis, the sample was inserted into a standard rectangular cavity in an EMX 71 X-band EPR spectrometer with $100 \mathrm{kHz}$ magnetic field modulator operating at room temperature.

The optical measurements were performed by diffuse reflection over the 250 to $800 \mathrm{~nm}$ wavelength range. The reflection spectrum was measured using a UV-vis-near infrared spectrometer (Lambda-950) equipped with an integrating sphere.

Finally, the radiocatalytic activity of the synthesized samples was evaluated through the degradation of methylene blue (MB) in aqueous solution under gamma-ray irradiation at doses varying from 10 to 1500 Gy using the Tunisian Cobalt-60 radiation facility at a $80 \mathrm{~Gy} / \mathrm{min}$ dose rate $[38,39]$. This dose rate was determined by alanine dosimeters irradiated by the facility and returned to Aerial for dose rate assessment.

In a typical experiment, a $10 \mathrm{mg} / \mathrm{l}$ aqueous solution of $\mathrm{MB}$ was mixed with the catalyst in a $100 \mathrm{ml}$ glass dish to obtain a solution suspension of $2 \mathrm{~g} / \mathrm{l}$. The mixture solution was initially stirred for about $2 \mathrm{~h}$ in the dark, to reach the adsorption equilibrium between $\mathrm{MB}$ and the powder catalyst surface. The MB concentration in the solution after the radiocatalysis reaction was estimated by using a UV-vis spectrophotometer (IC6400) and measuring the intensity maximum of the MB absorption peak at about $620 \mathrm{~nm}$.

\section{Results and discussion}

\subsection{Microstructural analysis}

XRD was used as a first characterization step to identify the structures of the crystalline phases present in the powders and to monitor any possible structural changes upon heat 
treatment and doping. The presence of a possible second phase was also looked for. Fig. 1 shows XRD patterns of the $\mathrm{Cu}-\mathrm{TiO}_{2}$ samples annealed at $600^{\circ} \mathrm{C}$. Importantly, we note that powders with 0-3 at.\% $\mathrm{Cu}$ concentration are a mixture of anatase and rutile phases without any detected additional phase. The fraction of the rutile phase increases with doping levels, from $20 \%$ for undoped $\mathrm{TiO}_{2}$ to $44 \%$ for $3 \mathrm{at} . \% \mathrm{Cu}-\mathrm{TiO}_{2}$. Therefore, it is clear that within this doping level range, the $\mathrm{Cu}$ doping promotes the anatase-to-rutile phase transition. This may be caused by the substitution of $\mathrm{Cu}^{2+}$ ions for $\mathrm{Ti}^{4+}$ ions within the anatase structural framework. Indeed, it is a well-known fact that the $\mathrm{TiO}_{2}$ anatase structure is metastable with respect to rutile. In both rutile and anatase, $\mathrm{Ti}$ is six-fold coordinated, but the number of shared octahedral edges increases from two in rutile to four in anatase [40]. The tolerance of the $\mathrm{TiO}_{2}$ structure to $\mathrm{Cu}$ doping can be qualitatively related to the local environment of $\mathrm{Ti}$ and the introduced strain. When $\mathrm{Cu}^{2+}$ ions enter the $\mathrm{TiO}_{2}$ lattice, substituting for $\mathrm{Ti}^{4+}$ ions, the ion charges should be compensated by an increase in oxygen vacancies, that act as nucleation sites for the anatase-to-rutile transformation. At the annealing temperature of $600^{\circ} \mathrm{C}$, these defects promote the transition from a metastable anatase phase to a more stable phase, more tolerant of defects, i.e. rutile. At a higher $\mathrm{Cu}$ doping level (6 at.\%) we note the almost complete disappearance of the rutile phase and the appearance of an additional phase identified as $\mathrm{CuO}$. The amount of this phase increases with $\mathrm{Cu}$ concentration. Once part of the $\mathrm{Cu}^{2+}$ ions is segregated outside the $\mathrm{TiO}_{2}$ structure, the number of oxygen vacancies decreases, leading to the inhibition of the anatase-to-rutile transformation. Other notable changes were observed: the estimated "a $(=\mathrm{b})$ " and "c" lattice parameters for undoped $\mathrm{TiO}_{2}$ powder are respectively $3.781 \AA$ and $9.478 \AA$ in the anatase structure and $4.592 \AA$ and $2.957 \AA$ in rutile. With the increase in $\mathrm{Cu}^{2+}$ concentration from 0 to 3 at.\%, the value of these lattice parameters hardly changes. Upon further increase of the $\mathrm{Cu}^{2+}$ concentration, only anatase crystallites are observed (as already mentioned), accompanied by a shift of the (101) and (200) reflections 
toward larger angles. According to [9], this shift may reflect the interstitial incorporation of $\mathrm{Cu}^{2+}$ ions within the $\mathrm{TiO}_{2}$ lattice. Such incorporation is promoted by an excess of copper. Interstitial doping generates stress in the anatase structure. Moreover, it does not provide additional oxygen vacancies and therefore inhibits the transition to the rutile phase. XRD measurements on pure $\mathrm{TiO}_{2}$ and $\mathrm{Cu}-\mathrm{TiO}_{2}$ sol-gel powders annealed at $400^{\circ} \mathrm{C}$ (not shown here) exhibit only diffraction peaks corresponding to the anatase phase without any secondary phase nor any notable change in lattice parameter, within the detection limits of XRD measurements.

The average crystallite size as a function of the $\mathrm{Cu}$ levels for samples annealed at $400^{\circ} \mathrm{C}$ and $600^{\circ} \mathrm{C}$ (Fig. 2) has been evaluated from the full width at half maximum (FWHM) of the most intense peaks (the (101) and (110) peaks for anatase and rutile respectively) using the Scherrer method [41]. As previously reported [6], the crystallite size increases with annealing temperature. Moreover, it appears that $\mathrm{Cu}$ incorporation has a different effect on crystal growth for each temperature. For samples annealed at $400^{\circ} \mathrm{C}$ the crystallites are smaller than those in the undoped material, by $25 \%$ for the $3 \mathrm{at} . \% \mathrm{Cu}-\mathrm{TiO}_{2}$ sample, with no detectable change of lattice parameters. The crystallite size evolution according to the doping level must be related to the insertion of doping atoms in the $\mathrm{TiO}_{2}$ structure. The substitution of metal ions of lower valence values for $\mathrm{Ti}^{4+}$ increases the oxygen deficiency to maintain charge neutrality. The reduction in crystallite size could be due to the formation of oxygen vacancies. In fact, defects can influence considerably the nucleation, growth, and structure of crystals [42, 43]. For samples annealed at $600^{\circ} \mathrm{C}$, the opposite is observed: for a doping level not exceeding 3 at.\%, doping leads to an increase in the average crystallite size (in both rutile and anatase phases). This result will be further discussed following a nano-structural study (see section 3.2). For both annealing temperatures and at a high $\mathrm{Cu}$ doping level (> 6 at.\%) a slight decrease in the size of the crystallites (present only in the anatase phase) is observed. Such a 
relative reduction in crystallite size in the presence of segregation of copper cations and/or a copper oxide additional phase at the grain boundaries has already been observed for Co-doped $\mathrm{TiO}_{2}$ [6]. This effect seems to increase with temperature as the relative difference between the crystallite size of doped and undoped samples increases with temperature. Above 6 at.\% the $\mathrm{Cu}^{2+}$ doping level does not show any significant effect on grain growth. Thus, we assume that at these high doping levels, the solubility limit of copper in the $\mathrm{TiO}_{2}$ structure is exceeded and $\mathrm{Cu}^{2+}$ ions are segregated to the grain surfaces. We will come back to this statement in the nanoscale analysis section.

\subsection{Nanoscale analysis}

As the energy-loss near-edge fine structures (ELNES) are sensitive to the oxidation state and to the bonding and local environment, it is not only possible to determine the chemical composition of the doped $\mathrm{TiO}_{2}$ samples, but also to sort out spectral signatures of the copper oxidation state and to locally identify the $\mathrm{TiO}_{2}$ crystalline phase (anatase vs rutile) in the studied samples. Chemical analyses were performed by EELS in the spectrum-imaging mode, in which the focused beam is scanned over a region of interest and a whole spectrum is acquired at each position of the scan $[44,45]$. Such a spectrum-image contains typically 10000 spectra. These spectra can be processed individually, usually by removing the background and summing the intensity corresponding to a characteristic edge and thus building elemental maps. However, as this data set contains a lot of redundant information, it is often very useful to process it as a whole using multivariate statistical techniques [46]. We used principal component analysis (PCA) as a filtering method for separating meaningful signal components from noise. In a few favorable cases, we used spectral unmixing methods. These methods assume that the whole spectrum-image can be described by a few reference spectra, each individual spectrum of the original data cube being a linear combination of these 
basic components [47, 48]. We used Vertex Component Analysis [49] to perform this unmixing step.

TEM and high angle annular dark field (HAADF) STEM images of the 3 at. $\% \mathrm{Cu}-\mathrm{TiO}_{2}$ sample annealed at $400^{\circ} \mathrm{C}$ are displayed in Fig. 3(a) and Fig. 3(b) respectively, for two different areas in the sample. Typical samples are well crystallized and crystallites exhibit polyhedral shapes with a mean size around $10-15 \mathrm{~nm}$, in agreement with XRD investigations. The inspection of the diffraction pattern confirms the anatase structure of the prepared samples with no detectable trace of the rutile phase. The $\mathrm{Ti}, \mathrm{O}$ and $\mathrm{Cu}$ elemental maps extracted from the EELS spectra acquired in the spectrum-imaging mode are shown in Fig. 3(c, d, e) respectively. Fig. 3 also shows the presence of metallic copper nanoparticles of size less than $2 \mathrm{~nm}$ (indicated by an arrow in Fig. 3(b)) which are not detected by XRD. The corresponding EELS $\mathrm{Cu} \mathrm{L}_{2,3}$ spectrum is shown and labeled (1) in Fig. 3(f). The $\mathrm{Cu}-\mathrm{L}_{2,3}$ spectrum from the square region, labeled (2) in Fig. 3(e), displays a lower signal-to-noise ratio and characteristic features of $\mathrm{Cu}^{2+}\left(\mathbf{F i g}\right.$. 3(f)). In fact, the $\mathrm{Cu}-\mathrm{L}_{2,3}$ edge shape, which reflects electronic transitions from $2 p$ to $3 \mathrm{~d}$ levels, is very sensitive to the oxidation state of the copper ion. The absorption edge of metallic copper $\mathrm{Cu}^{0}(\mathrm{~d} 10 \mathrm{~s} 1)$ exhibits a typical step like shape, while for $\mathrm{Cu}^{2+}(\mathrm{d} 9 \mathrm{~s} 0)$ most of the intensity in the near-edge region is concentrated in two narrow peaks, called $\mathrm{L}_{3}$ and $\mathrm{L}_{2}$ white lines. The $\mathrm{Cu}^{2+} \mathrm{L}$ edge threshold is also shifted to lower energy by around $2 \mathrm{eV}$ in comparison to the metallic state. It should be noted that the $\mathrm{Cu}^{1+}(\mathrm{d} 10 \mathrm{~s} 0)$ ELNES (not shown here) exhibits an increase in $\mathrm{L}_{3}$ white line intensity in comparison to metallic copper, but no chemical shift [50].

Fig. 4(a) shows a higher magnification TEM image together with its corresponding selected area electron diffraction (SAED) pattern of 6 at. $\% \mathrm{Cu}-\mathrm{TiO}_{2}$ annealed at $400^{\circ} \mathrm{C}$. The SAED pattern confirms the anatase structure of these polycrystalline powders [6]. We also note the presence of grain boundaries. Elemental maps as extracted from EELS spectrum- 
images of the region of interest associated with the HAADF image displayed in Fig. 4(b), are shown in Fig. 4(c, d) for the energy regions including the $\mathrm{Ti}-\mathrm{L}_{2,3}$ and $\mathrm{Cu}-\mathrm{L}_{2,3}$ edges respectively. These elemental maps show the presence of copper-rich nanoparticles (1-2 nm in diameter) at grain surfaces and a copper segregation at the grain boundaries. These secondary phases were not detected by XRD. In Fig. 4(e) we have manually applied two thresholds to the $\mathrm{Cu}$ map in order to separate the particles (visible in red) from the grain boundaries (in green). The spectra summed over the corresponding pixels are shown in Fig. 4(f). It appears that the grain boundaries contain mostly oxidized $\mathrm{Cu}^{2+}$ as indicated by the strong intensity in the white lines. The EELS fine structures corresponding to the particles exhibit a muchreduced white line intensity due to a strong contribution of a metallic $\mathrm{Cu}$ signal. From doping levels of about 3 at.\%, the $\mathrm{TiO}_{2}$ structure begins to be saturated with $\mathrm{Cu}$. The electrons trapped in oxygen vacancies (whose presence assures electron neutrality of the sample upon $\mathrm{Ti}^{4+}$ substitution) may be transferred to the $\mathrm{Cu}^{2+}$ ions segregated on the crystallite surface, resulting in metallic $\mathrm{Cu}$ formation.

Results from a nanoscale analysis of $\mathrm{Cu}-\mathrm{TiO}_{2}$ samples annealed at $600^{\circ} \mathrm{C}$ are summarized in Fig. 5. For samples with a $\mathrm{Cu}$ concentration of 3 at.\%, the typical crystallite morphology is shown in the HAADF images of Fig. 5(a) and Fig. 5(d). Large $\mathrm{TiO}_{2}$ particles with faceted shapes are observed. The mean particle size is found to be around $55 \mathrm{~nm}$ (in agreement with XRD analysis). The $\mathrm{Cu}$ map $\left(\mathrm{Cu}-\mathrm{L}_{2,3}\right.$ edge intensity map) of Fig. 5(b) clearly shows a copper segregation at the $\mathrm{TiO}_{2}$ crystallite surface and grain boundaries. As in the case of the $400^{\circ} \mathrm{C}$ annealed sample, we have applied a thresholding to the $\mathrm{Cu}$ map in order to separate the signal coming from the larger metallic copper particles (in red) from that of a weaker segregation at surfaces and grain boundaries (in green). $\mathrm{Cu}-\mathrm{L}_{2.3}$ edges thus obtained are presented in Fig. 5(c) and show slightly different oxidation states. In a few cases a strong copper segregation is observed at grain boundaries allowing for the signal extraction by 
statistical analysis of this secondary phase. Maps obtained after spectral unmixing of sets of spectra encompassing the Ti- $\mathrm{L}_{2,3}$ to $\mathrm{O}-\mathrm{K}$ energy region are presented in Fig. 5(e). These maps show the presence of both anatase and rutile phases (blue and green pixels in the image of Fig. 5(e)). A third component is extracted, which is characteristic of the grain boundaries (red pixels). The EELS components corresponding to these maps are presented in Fig. $\mathbf{5 ( f )}$. It is clearly possible to distinguish a rutile grain (in green) from the surrounding anatase ones (in blue). Fig. 5(g) and Fig. 5(h) show the result of a second VCA treatment applied when considering a larger energy range encompassing the $\mathrm{Ti}-\mathrm{L}_{2,3}, \mathrm{O}-\mathrm{K}$ and $\mathrm{Cu}-\mathrm{L}_{2,3}$ edges. The map associated with the VCA component related to $\mathrm{Cu}$ segregation at grain boundaries is shown in Fig. 5(g). The associated $\mathrm{Cu}-\mathrm{L}_{2,3}$ edge after background subtraction is shown in Fig. 5(h). The edge fine structures clearly indicate that the copper segregation at the grain boundaries involves a high copper oxidation state $\left(\mathrm{Cu}^{2+}\right)$. An elemental quantification of this VCA EELS component gives an estimated doping level of about 3 at.\% $\mathrm{Cu}$. This is much more than the measured $\mathrm{Cu}$ content within the grains, which is well below 1 at.\%. The remaining copper is probably present in an undetected additional phase.

The Ti- $\mathrm{L}_{2.3}$ ELNES corresponding to 3 at. $\% \mathrm{Cu}-\mathrm{TiO}_{2}$ samples annealed at $400^{\circ} \mathrm{C}$ and $600^{\circ} \mathrm{C}$ are presented in Fig. 6(a). All are composed of two main contributions, namely the $\mathrm{L}_{3}$ and $\mathrm{L}_{2}$ edges, separated by the $2 p$ core-hole spin-orbit coupling. The $\mathrm{L}_{3}$ and $\mathrm{L}_{2}$ edges are then both subdivided into two peaks by the strong crystal field splitting created by the surrounding oxygen atoms [51-54]. All the spectra have a similar form and are consistent with the $\mathrm{TiO}_{2}$ anatase structure for samples annealed at $400^{\circ} \mathrm{C}$ and with both anatase and rutile structures for samples annealed at $600^{\circ} \mathrm{C}$. A splitting reduction of the $\mathrm{Ti}-\mathrm{L}_{3}-\mathrm{e}_{\mathrm{g}}$ edge induced by $\mathrm{Cu}^{2+}$ incorporation is observed for both anatase and rutile structures. Fig. 6(b) shows EELS O-K edges for undoped and 3 at. $\% \mathrm{Cu}-\mathrm{TiO}_{2}$ annealed at $400^{\circ} \mathrm{C}$ and $600^{\circ} \mathrm{C}$. The spectra match well with the anatase and rutile $\mathrm{TiO}_{2}$ structures. They can be decomposed in two main 
spectroscopic regions labeled as (1) and (2). The pre-edge (1) results from hybridization of the oxygen $2 \mathrm{p}$ with the titanium $3 \mathrm{~d}$ orbitals. A stronger crystal field splitting is observed for rutile than anatase (associated with a $2.75 \mathrm{eV}$ and $2.5 \mathrm{eV} \mathrm{t} 2 \mathrm{~g}-\mathrm{e}_{\mathrm{g}}$ splitting respectively) [55]. (2) corresponds to electron transitions from $1 \mathrm{~s}$ to $2 \mathrm{p}$ oxygen states hybridized with titanium $4 \mathrm{~s}$ and $4 \mathrm{p}$ states that are sensitive to long-range connectivity changes between oxygen octahedra in the $\mathrm{TiO}_{2}$ structure. For all doped samples, the spectra of Fig. 6 show that the Ti- $\mathrm{L}_{2.3}$ and OK ELNES modifications due to the structural distortion induced by $\mathrm{Cu}^{2+}$ substitution are more marked at the grain boundaries, but are also present within the bulk of the $\mathrm{TiO}_{2}$ crystallites. Importantly, according to the recorded ELNES, we can rule out the presence of significant quantities of $\mathrm{Ti}^{3+}$ in all studied samples.

We now come back to the previous discussion on the particle size. For samples annealed at $400^{\circ} \mathrm{C}$, the average crystallite size decreases by $25 \%$ when the $\mathrm{Cu}$ content increases from 0 to 3 at. $\%$. The opposite is seen for samples annealed at $600^{\circ} \mathrm{C}$ : a strong increase of about $50 \%$ and $30 \%$ of the crystallite size, respectively in anatase and rutile phases is observed. Nanoscale investigation reveals that the $\mathrm{TiO}_{2}$ structure annealed at $600^{\circ} \mathrm{C}$ has a lower $\mathrm{Cu}$ saturation limit. Therefore, the true $\mathrm{Cu}$ doping concentration in the $\mathrm{TiO}_{2}$ lattice annealed at $600{ }^{\circ} \mathrm{C}$ is lower than that in samples annealed at $400^{\circ} \mathrm{C}$. Any size reduction due to growth inhibition in the presence of oxygen vacancies created by $\mathrm{Cu}^{2+}$ substitution is thus expected to be much more limited. However, oxygen vacancies and their effect on crystal growth cannot explain the crystallite size evolution discrepancy between both annealing temperatures.

In fact, the growth of such small nanoparticles is probably more dominated by surface processes than bulk ones. We speculate that the growth mechanism during annealing is affected by the presence of copper at the surface. For example, it has been suggested by Wu et al. for Fe-doped $\mathrm{TiO}_{2}$ samples that the presence of $\mathrm{Fe}^{3+}$ ions at the surface decreases the free 
energy and thereby reduces the thermodynamic driving energy of particle growth [56]. Alternatively, other mechanisms such as sintering [57] may be at the origin of an increase of particle size in the presence of copper.

\subsection{Electron paramagnetic resonance (EPR) study}

EPR spectroscopy analyses were performed in order to monitor the involved paramagnetic centers and to follow the valence state and the coordination environment of the doping ions as a function of $\mathrm{Cu}$ doping concentration in the $\mathrm{TiO}_{2}$ lattice. The evolution of the EPR signal of undoped and copper-doped $\mathrm{TiO}_{2}$ samples, annealed at $400^{\circ} \mathrm{C}$, are shown in Fig. 7. The sharp peak observed at $g=2.003$ closely approaches the free electron $g$ value $(g=2.002)$. This value is associated with single electrons trapped in oxygen vacancies from the $\mathrm{TiO}_{2}$ lattice [58]. Undoped samples have only this paramagnetic signal. For a doping level not exceeding 0.3 at. $\%$ of $\mathrm{Cu}^{2+}$ the intensity of this EPR peak increases and an asymmetric EPR signal shape appears whose intensity also increases. This EPR signal corresponds to the presence of $\mathrm{Cu}^{2+}(3 \mathrm{~d} 9)$ ions in octahedral coordination in the $\mathrm{TiO}_{2}$ lattice. This result is in agreement with that obtained by B. Choudhry et al. [11], confirming the substitution role of $\mathrm{Cu}^{2+}$ ions in the $\mathrm{TiO}_{2}$ network. The substitution of $\mathrm{Cu}^{2+}$ for $\mathrm{Ti}^{4+}$ ions in the $\mathrm{TiO}_{2}$ lattice leads to the formation of oxygen vacancies. It has been disclosed that for anatase the doping with a cation, such as $\mathrm{Cu}^{2+}, \mathrm{Co}^{2+}, \mathrm{Fe}^{3+}$, with a lower valence than that of the $\mathrm{Ti}^{4+}$ ion, introduces oxygen vacancies inhibiting the formation of $\mathrm{Ti}^{3+}$ ions $[11,15,6,56]$. We also note that these oxygen vacancy sites are electron traps $[59,60]$. Following the $\mathrm{Cu}^{2+}$ doping, the place occupied by the $\mathrm{O}^{2-}$ anion in the regular $\mathrm{TiO}_{2}$ lattice is taken by one or two free electrons, thus forming a donor level below the conduction band. It is demonstrated that these donor states in both anatase and rutile increase with increasing oxygen vacancies and can overlap the conduction band [61]. This may explain the great decrease in the band gap of $\mathrm{TiO}_{2}$ produced by $\mathrm{Cu}^{2+}$ doping. 
At a higher doping level (0.6at.\% $\left.\mathrm{Cu}-\mathrm{TiO}_{2}\right)$ a decrease in oxygen vacancy sites is noted, which is accompanied by an increase in the peak-to-peak height $(\mathrm{PPH})$ of the $\mathrm{Cu}^{2+}$ ion spectral signature (Fig. 7(b)). This may be due to the insertion of $\mathrm{Cu}^{2+}$ ions in the interstitial sites in addition to substitution. At doping levels up to 3 at. $\%$, the decrease in the oxygen vacancies PPH is more pronounced and is accompanied by a decrease in the $\mathrm{Cu}^{2+}$ ion signal PPH. The $\mathrm{Cu}^{2+}$ ion EPR signal also broadens, suggesting that a dipolar interaction among neighboring $\mathrm{Cu}^{2+}$ ions is taking place. The nanoscale investigation in section 3.2 reveals the presence of metallic copper nanoparticles in the grain boundaries at and above a 3 at.\% copper doping level. The electrons trapped $\mathrm{inTiO}_{2}$ oxygen vacancies can be transferred to the $\mathrm{Cu}^{2+}$ ions and metallic $\mathrm{Cu}$ is thus formed. This charge transfer can explain the decrease in the $\mathrm{Cu}^{2+}$ EPR signal PPH.

\subsection{Optical properties}

The optical properties of $\mathrm{Cu}-\mathrm{TiO}_{2}$ powders annealed at $400^{\circ} \mathrm{C}$ and $600^{\circ} \mathrm{C}$ were investigated by UV-vis spectroscopy in diffuse reflectance mode (DRS). The reflectance data $R \%$ was converted to the Kubelka-Munk function $F(R)$ by the equation: $F(R)=\frac{(1-R)^{2}}{2 R}$ which is proportional to the absorption coefficient $\propto$. The optical gap value is estimated using the Kubelka-Munk method combined with the Tauc relation [62]: $\propto \mathrm{h} v=\mathrm{A}\left(\mathrm{h} v-\mathrm{E}_{\mathrm{g}}\right)^{\mathrm{m}}$, where $\mathrm{h} v$ is the photon energy, $\mathrm{A}$ is an energy dependent constant and $\mathrm{m}$ an integer depending on the nature of the electronic transitions. For an indirect transition $\mathrm{m}=2$ and for a direct one $m=1 / 2$. By plotting $(F(R) . h v)^{\frac{1}{2}}$ as a function of energy excitation, we estimate the indirect energy band gap $E_{g}^{I}$ and likewise $(\mathrm{F}(\mathrm{R}) \cdot \mathrm{h} v)^{2}$ to estimate the direct band gap energy $E_{g}^{d}$. According to theoretical investigations, the substitution of $\mathrm{Cu}^{2+}$ for $\mathrm{Ti}^{4+}$ in anatase $(2 \mathrm{at} . \% \mathrm{Cu}$ doped $\mathrm{TiO}_{2}$ ) should lead to a decrease in the band gap, down to $1.7 \mathrm{eV}$, and an increase in the visible light absorption $[15,21]$. Indeed, as already mentioned, $\mathrm{Cu}^{2+}$ substitution in $\mathrm{TiO}_{2}$ is accompanied by the formation of oxygen vacancies to preserve electric neutrality. In a 
simplistic ionic model, along with $\mathrm{Cu}^{2+}$ acceptor defect states, oxygen donor band states are formed in the band gap [21]. Using more sophisticated models, the appearance of new states at the top of the valence band and the bottom of the conduction band after $\mathrm{Cu}^{2+}$ doping has been shown to result from the strong iono-covalency of the $\mathrm{Cu}-\mathrm{O}$ bonding which has a strong O2p-Cu3d hybridized character [15]. The absorbance spectra corresponding to the KubelkaMunk function versus wavelength and the band gap energy estimations for $\mathrm{Cu}-\mathrm{TiO}_{2}$ powders annealed at $400^{\circ} \mathrm{C}$ and $600^{\circ} \mathrm{C}$ are represented in Fig. 8. As expected, the insets in Fig. 8(a) and Fig. 8(b) show a general red shift in the UV-visible absorption spectra as a function of the $\mathrm{Cu}$ concentration. Undoped $\mathrm{TiO}_{2}$ exhibits strong absorption in the $\mathrm{UV}$ region and high transparency in the visible. Copper incorporation into the $\mathrm{TiO}_{2}$ lattice leads to a general shift in the UV-visible absorption spectra and to the creation of an increasingly (with $\mathrm{Cu}$ content) strong broad absorption band in the visible range. Two typical effects are observed: (i) the appearance of an absorption band between 400 and $500 \mathrm{~nm}$ that could be caused by the hybridization between $\mathrm{O} 2 \mathrm{p}$ from $\mathrm{TiO}_{2}$ and $\mathrm{Cu}^{2+} 3 \mathrm{~d}$ states $[4,11,15,21]$. This band has been shown also to appear due to charge transfer between $\mathrm{TiO}_{2}$ and $\mathrm{CuO}$ clusters [63] at the $\mathrm{TiO}_{2} / \mathrm{CuO}$ interface. The possible presence of metallic copper can also affect the absorbance of this material in the visible range, via plasmonic excitations. (ii) the appearance of abroad absorption band between 600 and $900 \mathrm{~nm}$, which is not observed in pure $\mathrm{TiO}_{2}$, and which is attributed to d-d transitions between the newly created energy levels at the top and bottom of the valence and conduction bands when $\mathrm{Cu}^{2+}$ is inserted into the $\mathrm{TiO}_{2}$ crystalline environment $[11,15]$. This typical behavior and these types of electronic transitions are consistent with those observed in the literature $[11,12]$ and indicate once more the substitution of $\mathrm{Ti}^{4+}$ by $\mathrm{Cu}^{2+}$. Resulting indirect $\left(E_{g}^{I}\right)$ and direct $\left(E_{g}^{d}\right)$ energy band gaps were estimated graphically in a first approximation via the Tauc relation [62] by extrapolation of the Tauc plot to the hv axis with a linear fit. The obtained values are shown in Fig. 8(c). In the $\mathrm{TiO}_{2}$ energy band 
structure, the top of the valence band originates mainly from $\mathrm{O}_{2 \mathrm{p}}$ states and the conduction band from $\mathrm{Ti}_{3 \mathrm{~d}}$ states. The presence of the extra element in the $\mathrm{TiO}_{2}$ lattice leads to a decrease of both direct and indirect band gaps. However, the most significant decrease is recorded for the indirect gap. For undoped samples, the band gap decreased slightly with increasing annealing temperature. This is in agreement with an increase in the rutile fraction with temperature. The presence of $\mathrm{Cu}^{2+}$ ions in the $\mathrm{TiO}_{2}$ structure has an even stronger effect on the band gap value reduction. In fact, we note that, at doping levels greater than 0.6 at.\%, samples annealed at $400{ }^{\circ} \mathrm{C}$ present the largest band gap reductions, peaking for the sample with 3 at.\% of copper $(1.5 \mathrm{eV})$. For $\mathrm{Cu}-\mathrm{TiO}_{2}$ samples annealed at $400^{\circ} \mathrm{C}$, when passing from a copper incorporation level of 3 at. $\%$ to 6 at.\% the intensity of the $400-500 \mathrm{~nm}$ absorption band increases while the 600-900 $\mathrm{nm}$ absorption band decreases (Fig. 8(a)). This suggests that the effective copper doping level in the 6 at. $\% \mathrm{Cu}-\mathrm{TiO}_{2}$ samples is lower than in 3 at. $\% \mathrm{Cu}-\mathrm{TiO}_{2}$. Indeed, at higher copper incorporation levels, microanalysis investigations confirm the segregation of copper oxide species at the surface of the crystallites.

For $\mathrm{Cu}-\mathrm{TiO}_{2}$ samples annealed at $600^{\circ} \mathrm{C}$ the incorporation of $\mathrm{Cu}^{2+}$ into the $\mathrm{TiO}_{2}$ structure also enhances the absorption by the catalyst in the visible range and induces a shift in the band gap to lower energies, though less pronounced than at $400^{\circ} \mathrm{C}$. According to the structural investigations, this finding can be attributed to the absorption caused by: (i) metallic copper clusters formed in grain boundaries, and (ii) the disordered, highly $\mathrm{Cu}$-doped $\mathrm{TiO}_{2}$ structure formed in the grain boundaries. These interpretations concern samples with doping level no greater than 3 at.\% of copper. The band gap decreases from 3.04 to $2.06 \mathrm{eV}$ and 1.98 $\mathrm{eV}$ for a doping level of 6 at.\% and 12 at.\% respectively. These variations are probably due to the presence of the $\mathrm{CuO}$ additional phase, which presents a gap of around $1.5 \mathrm{eV}$. As shown in Fig. 8(b), the contribution of this extra phase becomes rather large, which makes difficult the estimation of the gap through the methods used here on the diffuse reflectivity data. 


\subsection{Radiocatalytic activity evolution}

Fig. 9 shows the effects of radiolytic and radiocatalytic degradation of methylene blue (MB) as a function of gamma-ray doses. Fig. 9(a) shows the radiocatalytic degradation curves of $\mathrm{MB}$ as a function of dose for different $\mathrm{Cu}$ dopant content in $\mathrm{Cu}-\mathrm{TiO}_{2}$ catalysts calcined at $400^{\circ} \mathrm{C}$ for $6 \mathrm{~h}$. It is found that the degradation ratio of MB increases gradually with gamma dose. Under gamma irradiation and without any $\mathrm{TiO}_{2}$ catalyst, $\mathrm{MB}$ presents a similar degradation to that reported previously in the literature [64]. We then find that the insertion of copper into the $\mathrm{TiO}_{2}$ structure is beneficial to the radiocatalytic efficiency. In the presence of $\mathrm{Cu}-\mathrm{TiO}_{2}$ catalyst the $\mathrm{MB}$ degradation is about $25 \%$ higher than for undoped $\mathrm{TiO}_{2}$. At low gamma radiation doses ( $\leq 100 \mathrm{~Gy})$ the best degradation was obtained with 3 at. $\% \mathrm{Cu}-\mathrm{TiO}_{2}$. The presence of more copper in the $\mathrm{TiO}_{2}$ structure becomes slightly beneficial to the radiocatalytic activity only for high gamma radiation doses $(\geq 500$ Gy). The best radiocatalytic performance obtained for a 3 at. $\% \mathrm{Cu}-\mathrm{TiO}_{2}$ catalyst annealed at $400^{\circ} \mathrm{C}$ is probably due to the large reactive surface area and the low band gap energy values. As revealed by XRD measurements, at this doping level the produced samples have the smallest particle size and possibly have the highest specific surface area. In fact, as reported by many authors, e.g., [9], the specific surface area increases in inverse proportion to the sol-gel $\mathrm{TiO}_{2}$ particle size. Our structural and optical results revealed that $\mathrm{Cu}^{2+}$ internal doping of the $\mathrm{TiO}_{2}$ structure occurs and leads to a very low band gap. During the radiocatalytic process, gamma irradiation can also lead to the desorption of oxygen from the crystallite surface. The oxygen vacancies so created can form donor levels in the $\mathrm{TiO}_{2}$ forbidden band gap and can also act as traps for photogenerated electrons, thereby limiting the electron-hole recombination. With further copper doping level increases, $\mathrm{CuO}$ partially covers the surface of the $\mathrm{TiO}_{2}$ catalyst. $\mathrm{CuO} / \mathrm{TiO}_{2}$ heterostructures thus formed can facilitate the carrier separation and lead to improved radiocatalytic properties. 
Regarding the second set of $\mathrm{Cu}-\mathrm{TiO}_{2}$ samples annealed at $600^{\circ} \mathrm{C}$, the degradation rate as a function of gamma-ray dose is presented in Fig. 9(b). Pure $\mathrm{TiO}_{2}$ synthesized at $600^{\circ} \mathrm{C}$ presents better radiocatalytic performance than at $400^{\circ} \mathrm{C}$, even though for $\mathrm{TiO}_{2}$ catalysts it is generally accepted that anatase exhibits a higher photocatalytic activity than rutile [65]. Indeed, anatase is an indirect band gap semiconductor in contrast to rutile. This leads to a longer lifetime for photogenerated electrons and holes in anatase than in rutile. However, an optimal amount (not exceeding $20 \%$ ) of the rutile phase can result in enhanced catalytic properties. This synergistic effect (like that observed in commercial $\mathrm{TiO}_{2}$ powders, Degussa P25) is controlled by the band alignment between rutile and anatase, which is favorable to charge separation (see [66] for more details). Higher rutile percentages will generate trap sites for carrier recombination.

We observe at this temperature that $\mathrm{Cu}$ doping leads to a decrease in the radiocatalytic activity of the $\mathrm{TiO}_{2}$ catalyst. At this annealing temperature samples present a much lower specific surface than undoped ones (crystallites are about $45 \%$ larger after doping) and are densely covered with copper species, inhibiting the catalytic properties of $\mathrm{TiO}_{2}$. For samples doped with 3 at.\% of copper, structural investigations show an increase in the proportion of rutile (about 44\%). For higher doping levels, the specific surfaces are even smaller, but the return to a pure anatase phase can explain the slight increase in the MB catalytic degradation efficiency as compared to that obtained with 3 at. $\% \mathrm{Cu}-\mathrm{TiO}_{2}$ catalysts.

In summary, the best catalytic performance under gamma radiation was observed for copper-doped $\mathrm{TiO}_{2}$ samples annealed at $400^{\circ} \mathrm{C}$, copper being inserted in substitutional sites of the anatase structure. These samples have a high specific surface area and a small band gap. We note that during radiocatalysis, high-energy radiation is known to generate oxygen vacancies at the catalyst surface [67-69] that act as electron traps [61]. Such defects have been reported to affect surface adsorption of $\mathrm{H}_{2} \mathrm{O}$ and $\mathrm{O}_{2}$ on $\mathrm{TiO}_{2}$ and to promote $\mathrm{H}_{2} \mathrm{O}$ dissociation 
[70] and formation of hydroxyl groups, therefore accelerating the organic pollutant degradation process.

\section{Conclusions}

This work investigates a novel approach for destroying organic pollutants involving transition-metal-doped titania. Amongst the advantages of using ionizing radiation is the fact that it overcomes optical transparency limitations associated with visible and near-UV illumination. The performance of such systems depends strongly on the insertion of impurities in the $\mathrm{TiO}_{2}$ structure and their resulting distribution. We have shown that 3 at. $\% \mathrm{Cu}-\mathrm{TiO}_{2}$ catalysts annealed at $400^{\circ} \mathrm{C}$ present very small crystallites and therefore the highest specific surface, the most reduced band gap, due to $\mathrm{Cu}^{2+}$ insertion in the $\mathrm{TiO}_{2}$ lattice and so the best radiocatalytic performance. We suggest that oxygen vacancies generated during the radiocatalytic process form donor levels in the forbidden band gap of $\mathrm{TiO}_{2}$ and can also act as traps for the photogenerated electrons thereby limiting the electron-hole recombination. We also suggest that at higher annealing temperature, the much lower specific surface and the copper species present on the surfaces and at grain boundaries inhibit the radioacatalytic performances.

\section{References}

[1] M. A Henderson. A surface science perspective on $\mathrm{TiO}_{2}$ photocatalysis, Surf. Sci. Rep. 66 (2011) 185-278.

[2] P. Pichat, Fundamentals of $\mathrm{TiO}_{2}$ Photocatalysis. Consequences for Some Environmental Applications. Heterogeneous Photocatalysis, Part of the series Green Chemistry and Sustainable Technology, Springer, 2015, pp. 321-359. 
[3] B. Su, J. Xin, J. Li, T. Zheng, Q. Wang, Z. Lei, The role of multi-level structure for the improved photocatalytic performance of $\mathrm{TiO}_{2}$ fiber nanomaterial, Appl. Phys. A. 122 (2016) 32-39.

[4] G. Colon, M. Maicu, M.C. Hidalgo, J.A. Navı, Cu-doped $\mathrm{TiO}_{2}$ systems with improved photocatalytic activity, Appl. Catal. B Environ. 67 (2006) 41-51.

[5] J. Pan, S. P. Jiang. Synthesis of nitrogen doped faceted titanium dioxide in pure brookite phase with enhanced visible light photoactivity, J. Colloid Interface Sci. 469 (2016) 25-30.

[6] L. Samet, J. Bennasseur, R. Chtourou, K. March, O. Stephan, Heat treatment effect on the physical properties of cobalt doped $\mathrm{TiO}_{2}$ sol-gel materials, Mater. Charact. 85 (2013) 1-12.

[7] X. H. Xia, L. Lu, A. S.Walton, M.Ward, X. P.Han, R.Brydson, J. K. Luo, G. Shao, Origin of significant visible-light absorption properties of $\mathrm{Mn}$-doped $\mathrm{TiO}_{2}$ thin films, Acta Mater. 60 (2012) 1974-1985.

[8] W. P. Hudson, M. V. J. R. Carvalho, P. Hammer, C. R.Teodorico, $\mathrm{TiO}_{2}-\mathrm{Cu}$ photocatalysts: a study on the long- and short-range chemical environment of the dopant, J. Mater. Sci.48 (2013) 3904-3912.

[9] T. Aguilar, J. Navas, R. Alcántara, C. Fernández-Lorenzo, J. J. Gallardo, G. Blanco, J. Martín-Calleja, A route for the synthesis of $\mathrm{Cu}$-doped $\mathrm{TiO}_{2}$ nanoparticles with a very low band gap, Chem. Phys. Lett. 571 (2013) 49-53.

[10] I. Ganesh, P. P. Kumar, I. Annapoorna, J.M. Sumliner, M. Ramakrishna, N.Y. Hebalkar, G. Padmanabham, G. Sundararajan, Preparation and characterization of $\mathrm{Cu}$-doped $\mathrm{TiO}_{2}$ materials for electrochemical, and photocatalytic applications, Appl. Surf. Sci. 293 (2014) 229-247. 
[11] B. Choudhury, M. Dey, A. Choudhury, Defect generation, d-d transition, and band gap reduction in $\mathrm{Cu}$-doped $\mathrm{TiO}_{2}$ nanoparticles, Int. Nano Lett. 3 (2013) 25-33.

[12] C. Karunakaran, G. Abiramasundari, P. Gomathisankar, G. Manikandan, V. Anandi, $\mathrm{Cu}$-doped $\mathrm{TiO}_{2}$ nanoparticles for photocatalytic disinfection of bacteria under visible light, J. Colloid Interface Sci. 352 (2010) 68-74.

[13] O. Zuas, H. Budiman, Synthesis of nanostructured Copper-doped titania and its properties, Nano-Micro Lett. 5 (2013) 26-33.

[14] Q. Hu, J. Huang, G. Li, Y. Jiang, H. Lan, W. Guo, Y. Cao, Origin of the improved photocatalytic activity of $\mathrm{Cu}$ incorporated $\mathrm{TiO}_{2}$ for hydrogen generation from water, Appl. Surf. Sci. 382 (2016) 170-177.

[15] J. Navas, A.S. Coronilla, T. Aguilar, N.C. Hernandez, D. Santos, J.S. Marquez, D. Zorrilla,C.F. Lorenzo, R. Alcantara, J.M.Calleja, Experimental and theoretical study of the electronic properties of $\mathrm{Cu}$-doped anatase $\mathrm{TiO}_{2}$, Phys. Chem. Chem. Phys. 16 (2014) 3835-3845.

[16] M. C. Wu, P.Y. Wu, T. H. Lin, T. F. Lin. Photocatalytic performance of Cu-doped $\mathrm{TiO}_{2}$ nanofibers treated by the hydrothermal synthesis and air-thermal treatment, Appl. Surf. Sci. 430 (2018) 390-398.

[17] R. Yin, L. Ling, Y. Xiang, Y. Yang, A. D. Bokare, C. Shang. Enhanced photocatalytic reduction of chromium (VI) by $\mathrm{Cu}$-doped $\mathrm{TiO}_{2}$ under $\mathrm{UV}$-A irradiation.

Sep. Purif. Technol. 190 (2018) 53-59.

[18] J. Vargas, S. Coste, A. Garcia-Murillo, F. Carillo, A. Kassiba, Effects of metal doping $(\mathrm{Cu}, \mathrm{Ag}, \mathrm{Eu})$ on the electronic and optical behavior of nanostructured $\mathrm{TiO}_{2}$, J. Alloys Compd. 710 (2017) 355-363. 
[19] W. Chakhari, J. Ben Naceur, S. Ben Taieb, I. Ben Assaker, R. Chtourou, Fe-doped $\mathrm{TiO}_{2}$ nanorods with enhanced electrochemical properties as efficient photoanode materials, J. Alloys Compd. 708 (2017) 862-870.

[20] H. C. Huang, C. L. Yang, M. S. Wang, X. G. Ma. Enhanced photocatalytic performance of anatase $\mathrm{TiO}_{2}$ substitutionally co-doped with La and N, Sol. Energy Mater. Sol. Cells. 170 (2017) 233-238.

[21] A. Dashora, N. Patel, D.C. Kothari, B.L. Ahuja, A. Miotello, Formation of an intermediateband in the energy gap of $\mathrm{TiO}_{2}$ by $\mathrm{Cu}-\mathrm{N}$-codoping: first principles study and experimental evidence, Sol. Energy Mater. Sol. Cells.125 (2014) 120-126.

[22] W. Fang, M. Xing, J. Zhang. Modifications on reduced titanium dioxide photocatalysts: A review, J. Photochem. Photobiol. C. 32 (2017) 21-39.

[23] M.G. Méndez-Medrano, E. Kowalska, A. Lehoux, A. Herissan, B. Ohtani, D. Bahena, V. Briois, C. Colbeau-Justin, J.L. Rodríguez-López, H. Remita. Surface modification of $\mathrm{TiO}_{2}$ with $\mathrm{Ag}$ nanoparticles and $\mathrm{CuO}$ nanoclusters for Application in Photocatalysis. J. Phys. Chem. C. 120 (2016) 5143-5154.

[24] Q. Wang, Q. Yuan, Z. Liu, R. Jin, Y. Cui, S. Gao. Ultrasound-assisted synthesis and solar-light-driven photoelectrocatalytic activity of $\mathrm{CdS}$ sensitized $\mathrm{TiO}_{2}$ nanotube array photocatalysts, Sep. Purif. Technol. 194 (2018) 216-221.

[25] M. Yang, L. Zhang, B. Jin, L. Huang, Y. Gan, Enhanced photoelectrochemical properties and water splitting activity of self-ordered $\mathrm{MoO}_{3}-\mathrm{TiO}_{2}$ nanotubes, Appl. Surf. Sci. 364 (2016) 410-415.

[26] X. Wang, Y. Zhao, K. Mølhave, H. Sun. Engineering the Surface/Interface Structures of Titanium Dioxide Micro and Nano Architectures towards Environmental and Electrochemical Applications, Nanomaterials. 7 (2017) 1-30. 
[27] R. Long, N. J. English, New Insights into the band gap narrowing of (N, P)codoped $\mathrm{TiO}_{2}$ from hybrid density functional theory calculations, ChemPhysChem. 12 (2011) 2604-2608.

[28] R. Long, N. J. English, Electronic structure of cation-codoped $\mathrm{TiO}_{2}$ for visible-light photocatalysts applications from hybrid density functional theory calculations, Appl. Phys. Lett. 98 (2011)142103-142105.

[29] M. Logar, I. Bracko, A. Potocnik, B. Jancar, $\mathrm{Cu}$ and CuO/Titanate nanobelt based network assemblies for enhanced visible light photocatalysis, Langmuir. 30 (2014) 4852-4862.

[30] Z. J. Li, Y. Qu, G. W. He, M. Humayun, S. Y Chen, L.Q. Jing, Enhanced visiblelight activities for PEC water reduction of $\mathrm{CuO}$ nanoplates by coupling with anatase $\mathrm{TiO}_{2}$ and mechanism, Appl. Surf.Sci. 351 (2015) 681-685.

[31] Q. Huang, F. Kang, H. Liu, Q. Li, X.D. Xiao, Highly aligned $\mathrm{Cu}_{2} \mathrm{O} / \mathrm{CuO} / \mathrm{TiO}_{2}$ core/shell nanowire arrays as photocathodes for water photoelectrolysis, J. Mater. Chem. A. (2013) 2418-2425.

[32] Q. Hu, J. Huang, G. Li, J. Chen, Z. Zhang, Z. Deng, Y. Jiang, W. Guo, Y. Cao, Effective water splitting using $\mathrm{CuO}_{\mathrm{x}} / \mathrm{TiO}_{2}$ composite films: Role of $\mathrm{Cu}$ species and content in hydrogen generation, Appl. Surf. Sci. 369 (2016) 201-206 .

[33] N.L. Wu, M.S. Lee, Enhanced $\mathrm{TiO}_{2}$ photocatalysis by $\mathrm{Cu}$ in hydrogen production from aqueous methanol solution, Int. J. Hydrogen Energy. 29 (2004) 1601-1605.

[34] P. G. Hoertz, D. Magnus-Aryitey, V. Gupta, C. Norton, S. Doorn,T. Ennis. Photocatalytic and radiocatalytic nanomaterials for the degradation of organic species, Radiat. Phys. Chem. 84 (2013) 51-58. 
[35] A. Cecal, M. Goanta, M. Palamaru, T. Stoicescu, K. Popa, A. Paraschivescu, V. Anita, Use of some oxides in radiolytical decomposition of water, Radiat. Phys. Chem. 62 (2001) 333-336.

[36] F. Follut, N. Karpel Vel Leitner, Radiolysis of aquous 4-nitrophenol solution with $\mathrm{Al}_{2} \mathrm{O}_{3}$ or $\mathrm{TiO}_{2}$ nanoprticules,Chemosphere. 66 (2007) 2114-2119.

[37] J.C. Gonzalez-Juarez, J. Jimenez-Becerril, Gamma radiation induced catalytic degradation of 4-chlorophenol using $\mathrm{SiO}_{2}, \mathrm{TiO}_{2}$ and $\mathrm{Al}_{2} \mathrm{O}_{3}$, Radiat. Phys. Chem.75 (2006) 768-772.

[38] F. Hosni, K. Farah, H. Kaouach, A. Louati, R. Chtourou, A.H. Hamzaoui, Effect of gamma-irradiation on the Colorimetric properties of epoxy-resin films: potential use in dosimetric application, Nucl. Instrum. Methods Phys. Res., Sect. B. 311 (2013) 1-4.

[39] F. Hosni, K. Farah, A. Mejri, A. Khayat, R.Chtourou, A. H. Hamzaoui, Dosimeter P. A study of the fractionation dose on the radiation response of Harwell Red-Perspex PMMA dosimeter, Nucl. Instrum. Methods Phys. Res., Sect. B. 290 (2012) 69 -71.

[40] J. Arbiol, J. Cerda, G. Dezanneau, A. Cirera, F. Peiro, A. Cornet, J. R. Morante, Effects of $\mathrm{Nb}$ doping on the $\mathrm{TiO}_{2}$ anatase-to-rutile phase transition, J. Appl. Phys. 92 (2002) 853-862.

[41] E. W. Nuffield, X-ray diffraction methods.,Wiley, New York,1966.

[42] V. W. A. De Villeneuve, R. P. Dullens, D. G. A. L. Aarts, , E. Groeneveld, J. H. Scherff, W.K. Kegel, H.N.W. Lekkerkerker, Colloidal Hard-Sphere Crystal Growth Frustrated by Large Spherical Impurities, Science. 309 (2005) 1231-1233.

[43] N. Kubota, Effect of Impurities on the Growth Kinetics of Crystals, Cryst. Res. Technol. 36 (2001) 749-769. 
[44] C. Jeanguillaume \& C. Colliex, Spectrum-image: the next step in EELS digital acquisition and processing, Ultramicroscopy.198928 (1989) 252-257.

[45] A. Gloter, V. Badjeck, L. Bocher, N. Brun, K. March, M. Marinova, M. Tencé, M. Walls, A. Zobelli, O. Stéphan, C. Colliex, Atomically resolved mapping of EELS fine structures, Mater. Sci. Semicond. Process. 65 (2017) 2-17.

[46] F. De La Peña, M. H. Berger, J. F. Hochepied, F. Dynys, O. Stephan, M. Walls, Mapping titanium and tin oxide phases using EELS: An application of independent component analysis, Ultramicroscopy.111 (2011) 169-176.

[47] N. Dobigeon, N. Brun, Blind Linear unmixing of EELS spectrum-images, Ultramicroscopy. 120 (2012) 25-34.

[48] N. Dobigeon, Y. Altmann, N. Brun, S. Moussaoui, Linear and non linearunmixing in hyperspectral imaging, in Resolving spectral mixtures - With application from ultrafast time-resolved spectroscopy to super resolution imaging, C. Ruckebusch,Data Handling in Science and Technology Series. 30, Ed. Oxford., U.K.: Elsevier. 30, 2016 pp. 185-224.

[49] J. M. P. Nascimento, J. M. Bioucas-Dias, Vertex component analysis: A fast algorithm to unmix hyperspectral data, IEEE Trans. Geosci. Remote Sens. 43(4) (2005) 898-910.

[50] M. Backahaus-Ricoult, L. Samet, M.F. Trichet, M.J. Hytch, D. Imhoff, Interfacial chemistry in internally oxidized (Cu, Mg)-alloys, J. Solid State Chem. 173 (2003) 172188.

[51] R. Brydson, H. Sauer, W. Engel, J. M.Thomas, E. Zeitler, N. Kosugill, H. Kurodall, Electron energy loss and x-ray absorption spectroscopy of rutile and anatase: a test of structural sensitivity, J. Phys.: Condens. Matter. 1 (1989) 797-812. 
[52] J. P. Corombette, F. Jollet, Ti2p X-ray absorption in tianium dioxides $\left(\mathrm{TiO}_{2}\right)$ : the influence of the cation site environment, J. Phys.: Condens. Matter. 6 (1994) 1081110821.

[53] G. S. Henderson, X. Liu, M. E. Fleet, A Ti-L edge X Ray absorption study of Tisilicate glasses, Phys. Chem. Miner. 29 (2002) 32-42.

[54] G. Bertoni, E. Beyers, J. Verbeeck, M. Mertens, P. Cool, E.F. Vansant, G. Van Tendeloo, Quantification of crystallineand amorphous content in porous $\mathrm{TiO}_{2}$ samples from electron energy loss spectroscopy, Ultramicroscopy. 106 (2006) 630635.

[55] A. Gloter, C. Ewels, P. Umek, D. Arcon, C. Colliex, Electronic structure of titaniabased nanotubes investigated by EELS spectroscopy, Phys. Rev. B: Condens. Matter Mater. Phys. 80 (2009) 035413-035419.

[56] Q. Wu, Q. Zheng, R. Van de Krol, Creating Oxygen Vacancies as a Novel Strategy To Form Tetrahedrally Coordinated $\mathrm{Ti}^{4+}$ in $\mathrm{Fe} / \mathrm{TiO}_{2}$ Nanoparticles, J. Phys. Chem. C. 116 (2012) 7219-7226.

[57] W. Tuichai, S. Danwittayakul, N. Chanlek, P. Thongbai, Effects of sintering temperature on microstructure and giant dielectric properties of $(\mathrm{V}+\mathrm{Ta})$ co-doped $\mathrm{TiO}_{2}$ ceramics, J. Alloys Compd.725 (2017) 310-317.

[58] Y. Sun, T. Egawa, L. Zhang, X. Yao, Novel method to directly prepare high-surfacearea anatase titania nanoparticles with trapped electrons on oxygen vacancies, J. Mater. Sci. Lett. 22 (2003) 799-802.

[59] H. Li, Y. Guo, J. Robertson, Calculation of $\mathrm{TiO}_{2}$ Surface and Subsurface Oxygen Vacancy by the Screened Exchange Functional, J. Phys. Chem. C. 119 (2015) 1816018166. 
[60] C. Papageorgiou Anthoula, S. Beglitis Nikolaos, L. Pang Chi, G. Teobaldi,C. Gregory, Q. Chen, J. Fisher Andrew, A. Hofer Werner, G. Thornton, Electron traps and their effect on the surface chemistry of $\mathrm{TiO}_{2}$ (110), PNAS. 107 (2010) 2391-2396.

[61] X. Pan, M. Q. Yang, X. Fu, N. Zhang, Y. Xu, Defective $\mathrm{TiO}_{2}$ with oxygen vacancies: synthesis, properties and photocatalytic applications, Nanoscale. 5 (2013) 3601-3614.

[62] S. Tandon, J. Gupta, Measurement of forbidden energy gap of semiconductor by diffuse reflectance technique, Phys. Status Solidi B. 38 (1970) 363-367.

[63] G. Li, N. M. Dimitrijevic, L. Chen, T. Rajh, Role of surface/interfacial $\mathrm{Cu}^{2+}$ sites in the photocatalytic activity of coupled $\mathrm{CuO}-\mathrm{TiO}_{2}$ nanocomposites, J. Phys. Chem. C. 112 (2008) 19040-19044.

[64] B. Zheng, C. Li, L. Jiang, L. Lizheng Liang, W. Pen, J. Niu, Degradation of Methylene Blue in aqueous solution by gamma irradiation, The 5 th International Conference on Bioinformatics and Biomedical Engineering (IEEE). (2011) 1-4.

[65] J. Zhang, P. Zhou, J. Liu, J. Yu, New understanding of the difference of photocatalytic activity among anatase, rutile and brookite $\mathrm{TiO}_{2}$, Phys. Chem. Chem. Phys. 16 (2014) 20382-20386.

[66] Y. Mi, Y. Weng, Band alignement and contrillable elecron migration between rutile and anatase $\mathrm{TiO}_{2}$, Sci. Rep. 11482 (2015) 1-10.

[67] L.-Q. Wang, D. R. Baer, M. H. Engelhard, A. N. Shultz, The adsorption of liquid and vapor water on $\mathrm{TiO}_{2}(110)$ surfaces: the role of defects, Surf. Sci. 344 (1995) 237-250.

[68] S. Eriksen and R. G. Egdell, Electronic excitations at oxygen deficient $\mathrm{TiO}_{2}$ (110) surfaces: A study by EELS, Surf. Sci. 180 (1987) 263-27.

[69] M. L. Knotek, P. J. Feibelman, Ion Desorption by Core-Hole Auger Decay, Phys. Rev. Lett. 40 (1978) 964-967. 
[70] R. Schaub, P. Thostrup, N. Lopez, E. Lægsgaard, I. Stensgaard, J. K. Nørskov and F. Besenbacher, Oxygen Vacancies as Active Sites for Water Dissociation on Rutile $\mathrm{TiO}_{2}$ (110), Phys. Rev. Lett. 87 (2001) 266104-266108. 
Graphical Abstract (for review)
\[ 5 \mathrm{~nm} \]
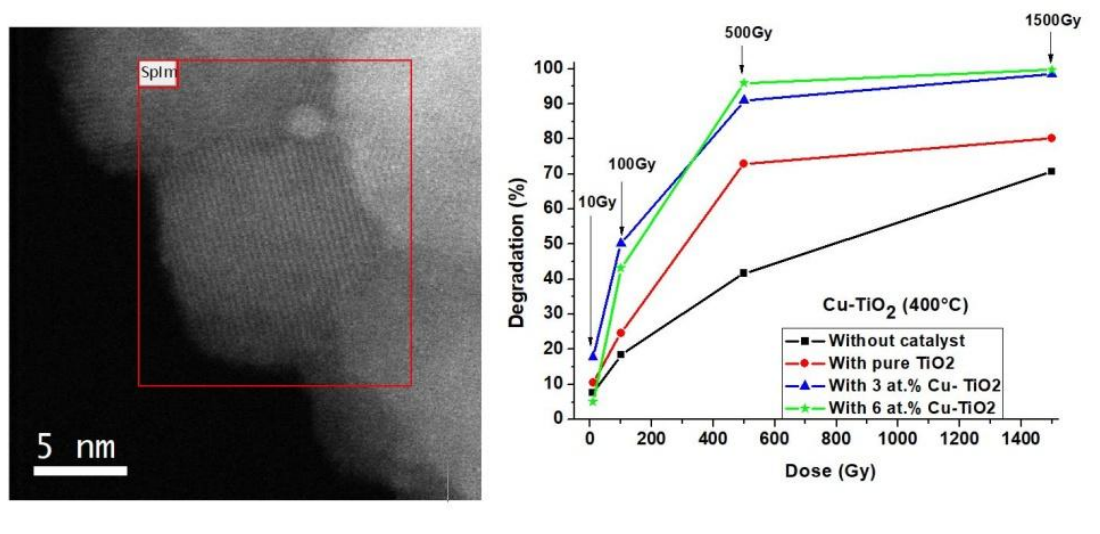

Graphical Abstract (for review)
\[ 5 \mathrm{~nm} \]

Graphical Abstract (for review)
\[ 5 \mathrm{~nm} \]

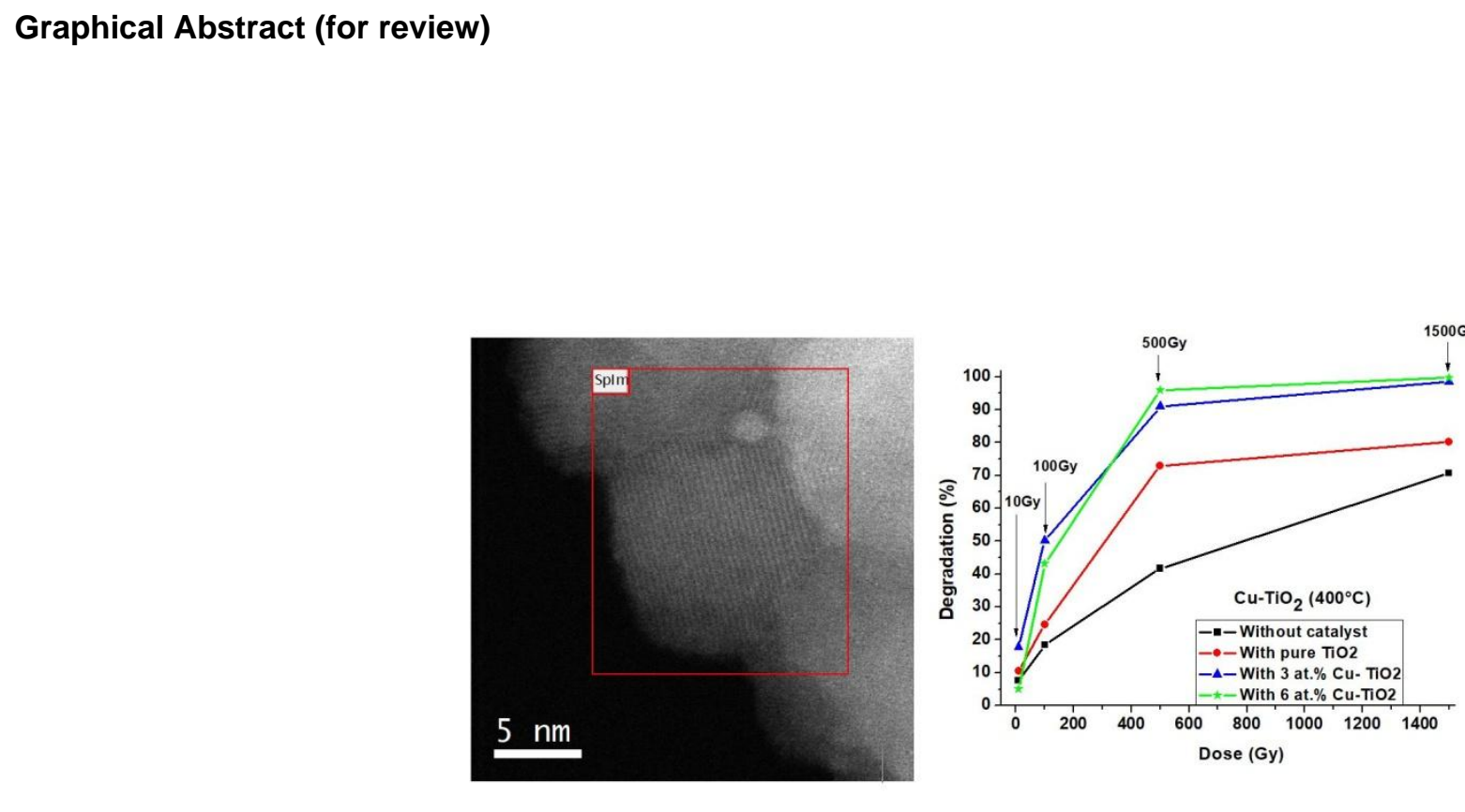

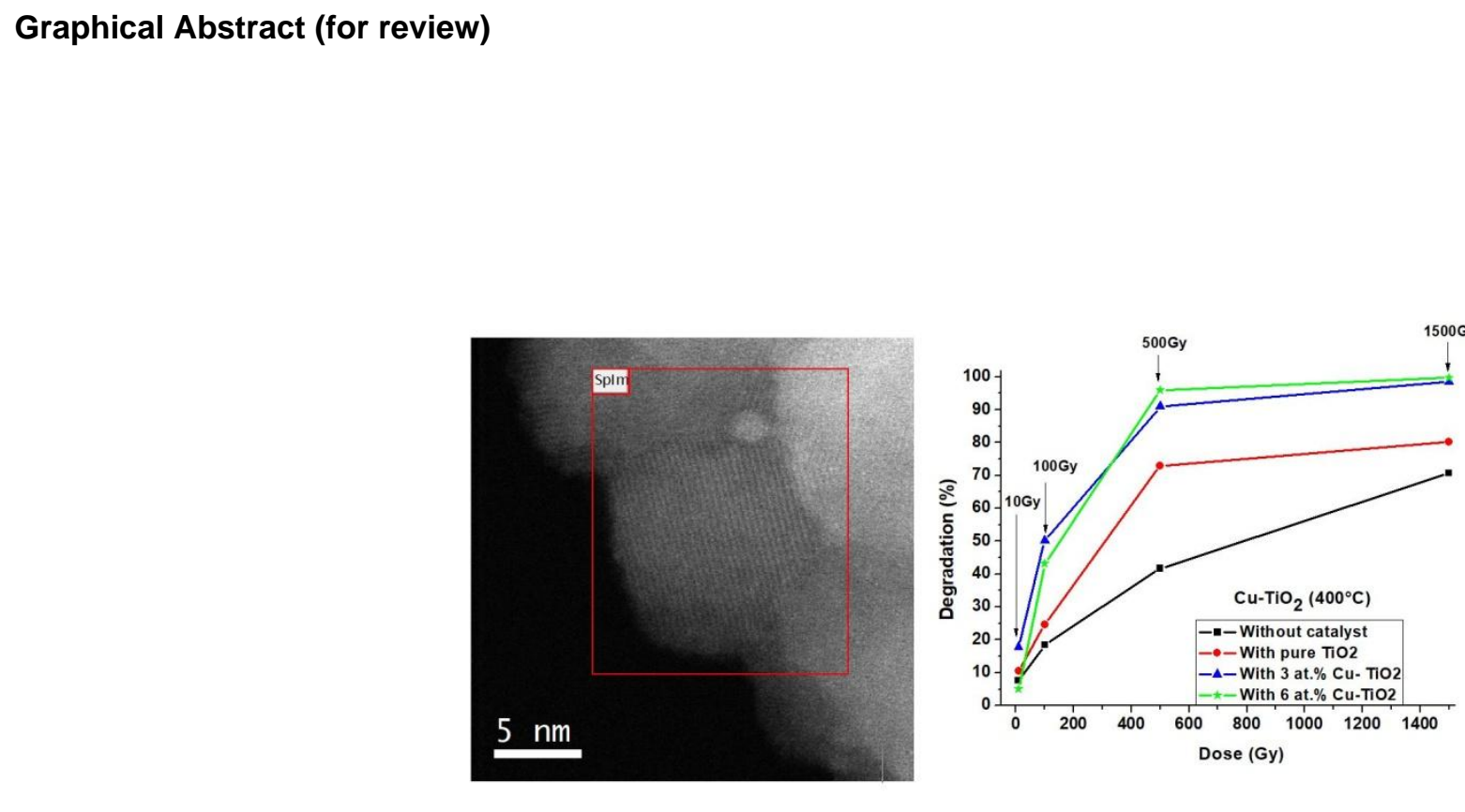

00Gy

.
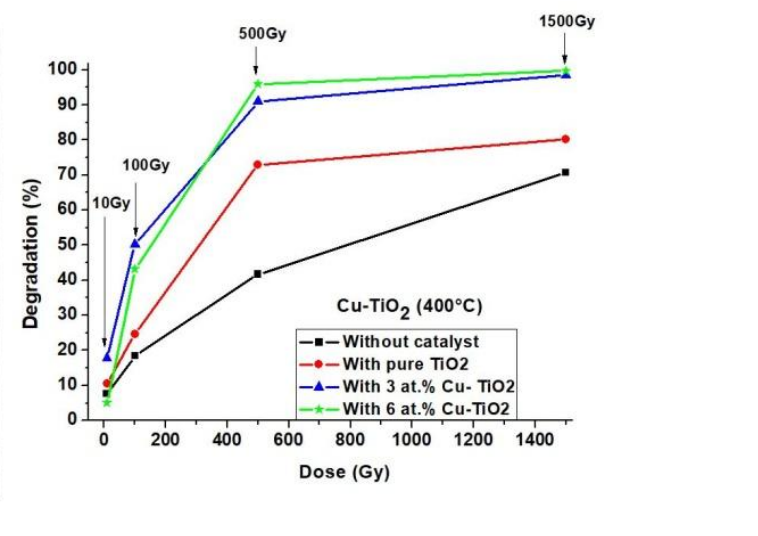

(1)

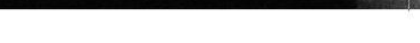

.

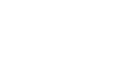




\section{Highlights :}

$\checkmark$ Copper doped and undoped $\mathrm{TiO}_{2}$ powders were prepared by sol-gel route.

$\checkmark$ Nanoscale analysis show evidence of internal doping by $\mathrm{Cu}^{2+}$ in the $\mathrm{TiO}_{2}$ sublattice.

$\checkmark$ Substitution reduce the optical band gap down to $1.5 \mathrm{eV}$.

$\checkmark$ Metallic copper segregation is formed at the crystallite surfaces.

$\checkmark$ Anatase $\mathrm{Cu}$ doped $\mathrm{TiO}_{2}$ improves significantly the radiocatalytic efficiency. 


\section{Figures captions:}

Fig. 1: (a) $\mathrm{XRD}$ patterns of undoped and $\mathrm{Cu}-\mathrm{TiO}_{2}$ powders annealed at $600^{\circ} \mathrm{C}$. (b) Enlarged view of the XRD patterns around the anatase (101) reflection (c) same for the (200) reflection.

Fig. 2: Crystallite size (a) and full-width at half-maximum (FWHM) estimation of the anatase (101) and rutile (110) peaks (b) for pure $\mathrm{TiO}_{2}$ and $\mathrm{Cu}-\mathrm{TiO}_{2}$ powders annealed at $400^{\circ} \mathrm{C}$ and $600^{\circ} \mathrm{C}$ versus $\mathrm{Cu}$ doping levels.

Fig. 3: Copper distribution characteristics in 3 at. $\% \mathrm{Cu}-\mathrm{TiO}_{2}$ samples annealed at $400^{\circ} \mathrm{C}$. (a) TEM micrograph and corresponding fast Fourier transform (FFT) pattern from a typical area. (b) HAADF image showing a nanometer size copper particle (arrow). (c) $\mathrm{Ti}$, (d) $\mathrm{O}$ and (e) $\mathrm{Cu}$ elemental maps from the area displayed in (b). (f) associated EELS Cu- $\mathrm{L}_{2.3}$ to the areas labelled (1) and (2) in (e).

Fig. 4: Copper distribution characteristics in 6 at. $\% \mathrm{Cu}-\mathrm{TiO}_{2}$ samples annealed at $400^{\circ} \mathrm{C}$. (a) TEM micrograph and the corresponding fast Fourier transform (FFT) pattern from a typical area. (b) HAADF image showing a large number of $\mathrm{Cu}$ particles decorating at grain boundaries or decorating the grain surface. (c) $\mathrm{Ti}$ and (d) $\mathrm{Cu}$ elemental maps from the area displayed in (b). (e) thresholding of the $\mathrm{Cu}$ map in order to separate the nanoparticles (visible in red) from the grain boundaries (in green). (f) the EELS Cu- $\mathrm{L}_{2.3}$ spectra summed over the corresponding nanoparticle pixels (1) and that at grain boundaries (2).

Fig. 5: Copper distribution characteristics in 3 at. $\% \mathrm{Cu}-\mathrm{TiO}_{2}$ samples annealed at $600^{\circ} \mathrm{C}$. (a) HAADF image and (b) $\mathrm{Cu}-\mathrm{L}_{2,3}$ intensity map with thresholding from a protruding grain to isolate the spectroscopic contribution from the nanoparticles (in red) to that from the grain surface and boundaries (in green). (c) associated $\mathrm{Cu}-\mathrm{L}_{2,3}$ spectra. (d) HAADF image of several adjacent grains. (e) Composite image after VCA processing of a spectrum image acquired from a reduced area and in the energy range of $\mathrm{Ti}-\mathrm{L}_{2,3}$ and $\mathrm{OK}$ edges. The blue, red and green pixels correspond to different $\mathrm{TiO}_{2}$ phases. (f) VCA component EELS spectra associated to (e). (g) VCA component map associated to $\mathrm{Cu}$, extracted from a spectrum image from the same reduced spatial area but encompassing the whole energy range of $\mathrm{Ti}^{-} \mathrm{L}_{2,3}, \mathrm{OK}$ and $\mathrm{Cu}-\mathrm{L}_{2,3}$ edges. (h) $\mathrm{Cu}-\mathrm{L}_{2,3}$ edge associated to the VCA map displayed in $(\mathrm{g})$.

Fig. 6: EELS for $\mathrm{Cu}-\mathrm{TiO}_{2}$ powders annealed at $400\left(\mathrm{Cu} 3\right.$ at.\%, $\mathrm{Cu} 6$ at.\%) and $600^{\circ} \mathrm{C}$ (Anatase: $\mathrm{Cu} 3$ at.\% (A), Rutile: $\mathrm{Cu} 3$ at.\% (R), grain boundaries $\mathrm{Cu} 3$ at.\% (GB) and $\mathrm{Cu} 6$ at.\%). (a) Ti-L $\mathrm{L}_{2,3}$ ELNES. (b) OK ELNES.

Fig. 7: EPR spectroscopy of $\mathrm{Cu}-\mathrm{TiO}_{2}$ catalysts annealed at $400^{\circ} \mathrm{C}$. EPR signal for (a) divalent copper ions $\left(\mathrm{Cu}^{2+}\right)$ and (b) oxygen vacancies (Vo). (c) Evolution of the peak-to-peak height of both signatures as a function of $\mathrm{Cu}$ doping levels.

Fig. 8: Plots of $(F(R) . h \gamma)^{1 / 2}$ versus $h \gamma$ for estimating the band gap energies for sol gel undoped and $\mathrm{Cu}-\mathrm{TiO}_{2}$ powders annealed at $400^{\circ} \mathrm{C}$ (a) and $600^{\circ} \mathrm{C}$ (b), insets display the absorption spectra. (c) Evolution of the direct and indirect band gap energy estimation versus $\mathrm{Cu}$ incorporated levels.

Fig. 9: $\mathrm{MB}$ degradation by radiocatalysis using pure and $\mathrm{Cu}-\mathrm{TiO}_{2}$ catalyst annealed at $400^{\circ} \mathrm{C}$ (a) and $600^{\circ} \mathrm{C}(\mathrm{b})$. 
Fig.1
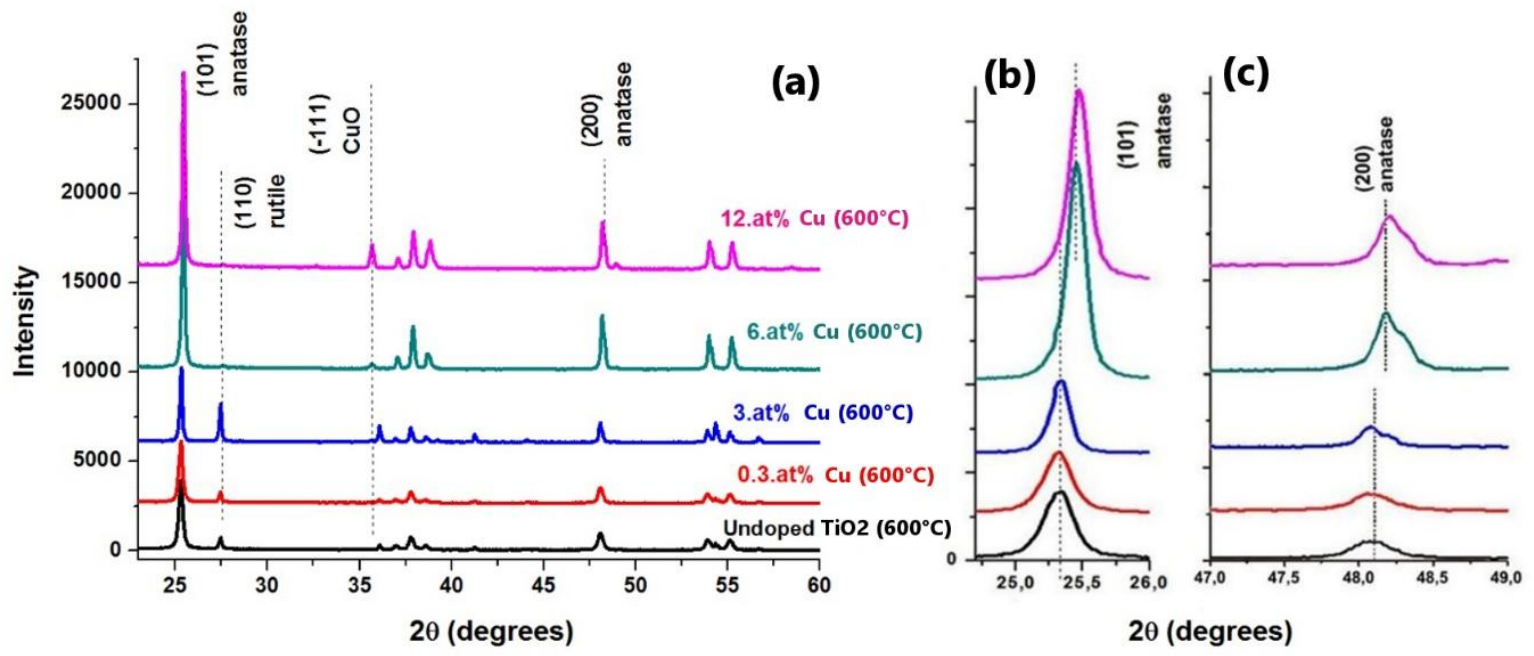
Fig. 2

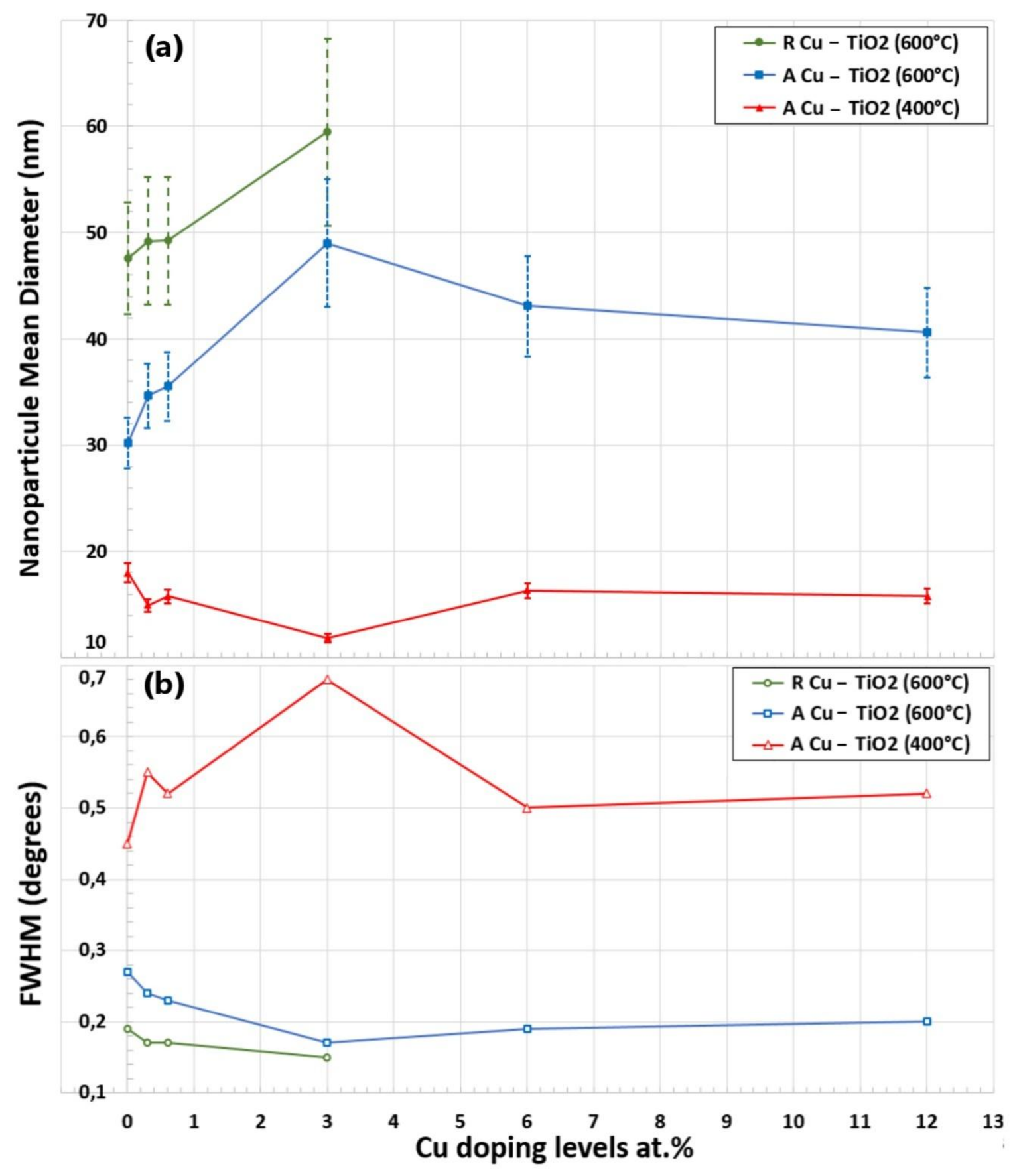


Fig.3
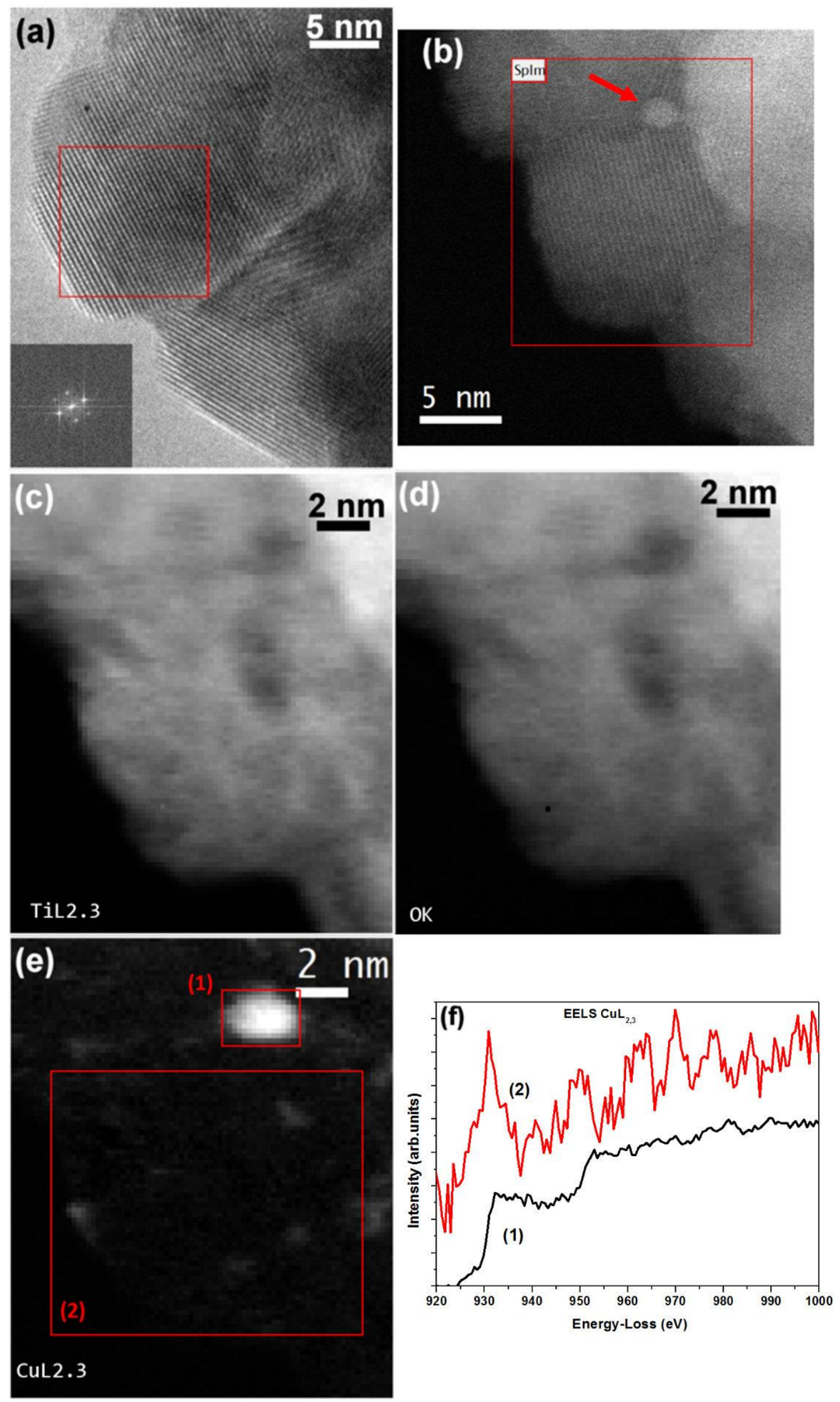
Fig.4
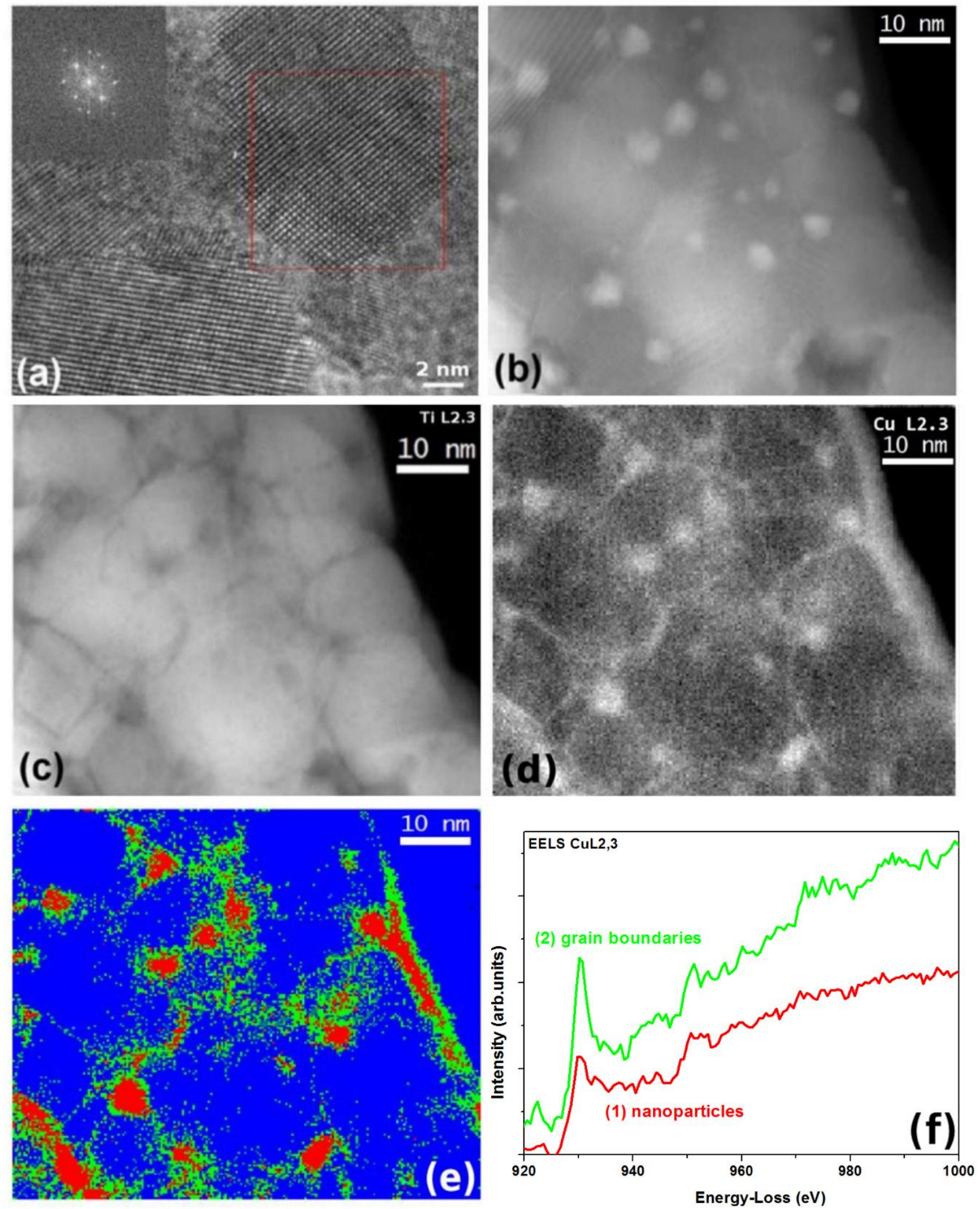
Fig.5

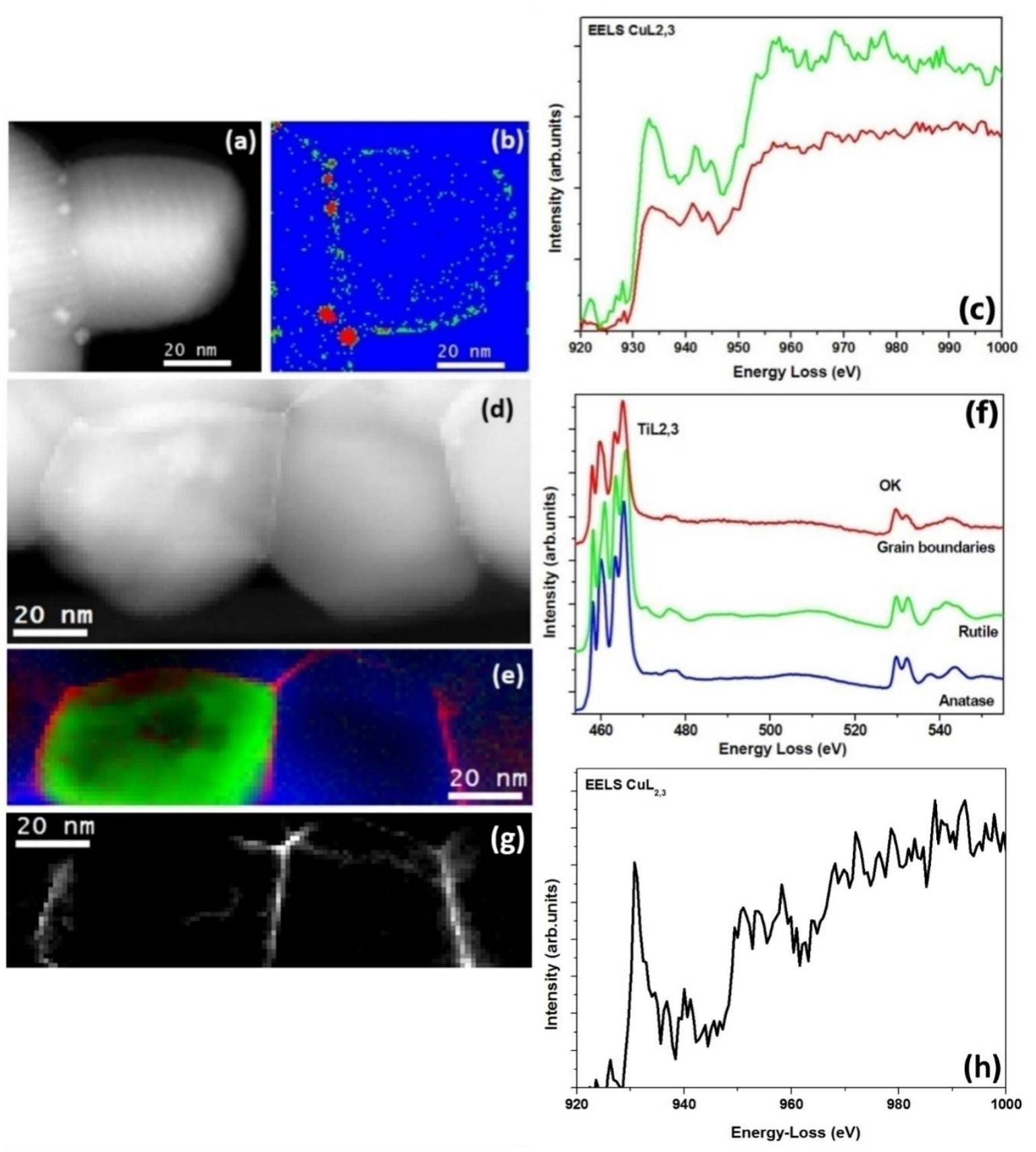


Fig.6
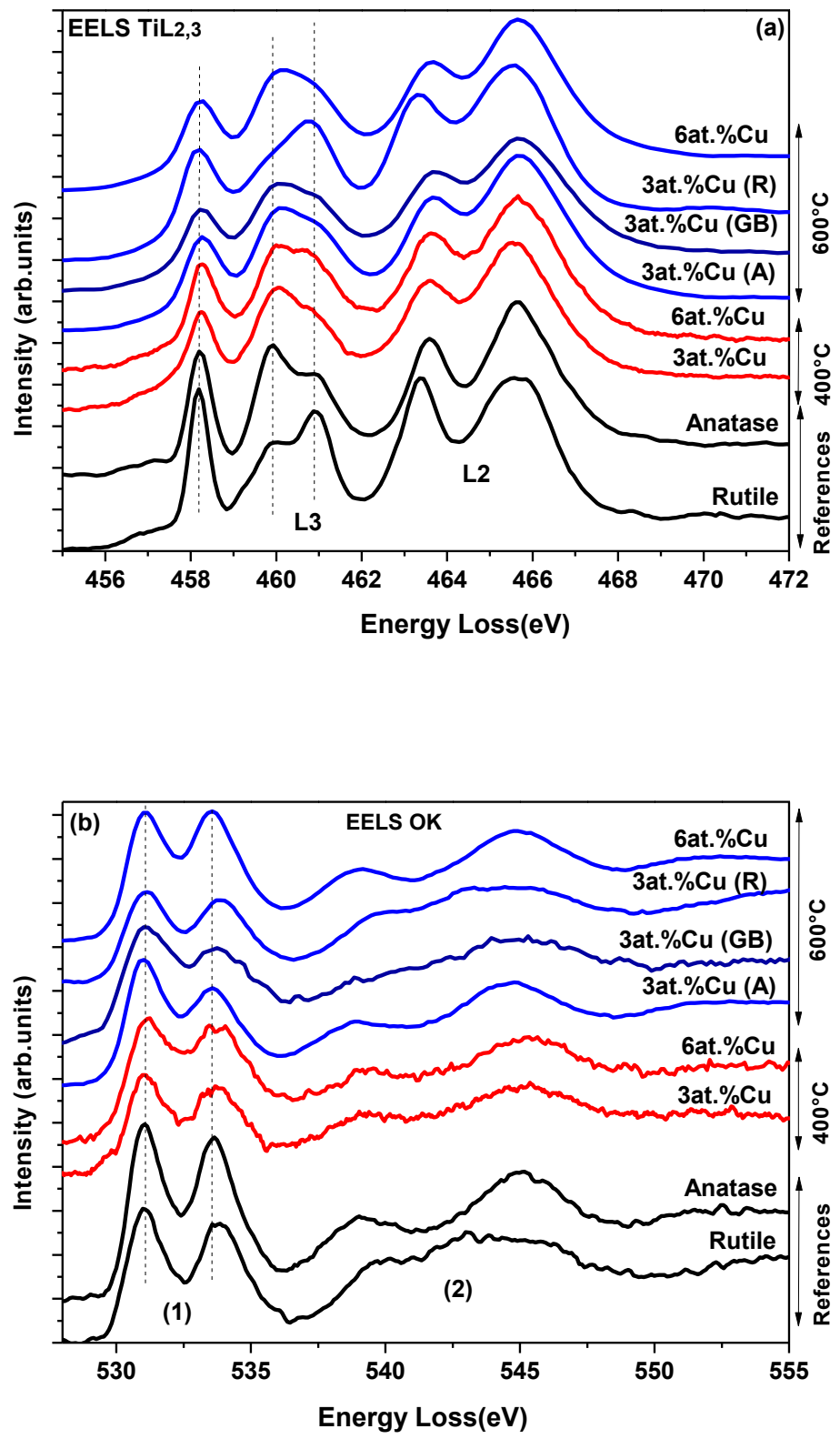
Fig.7
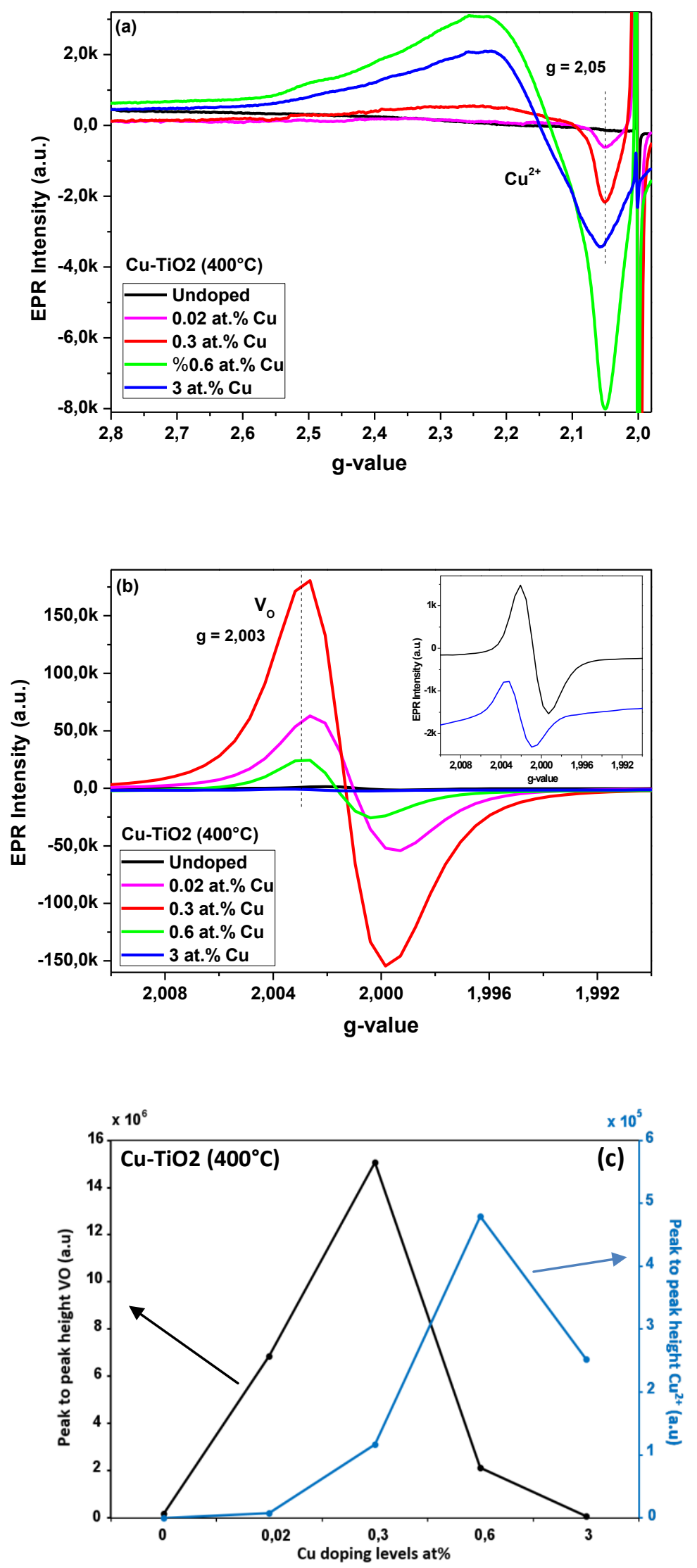
Fig.8
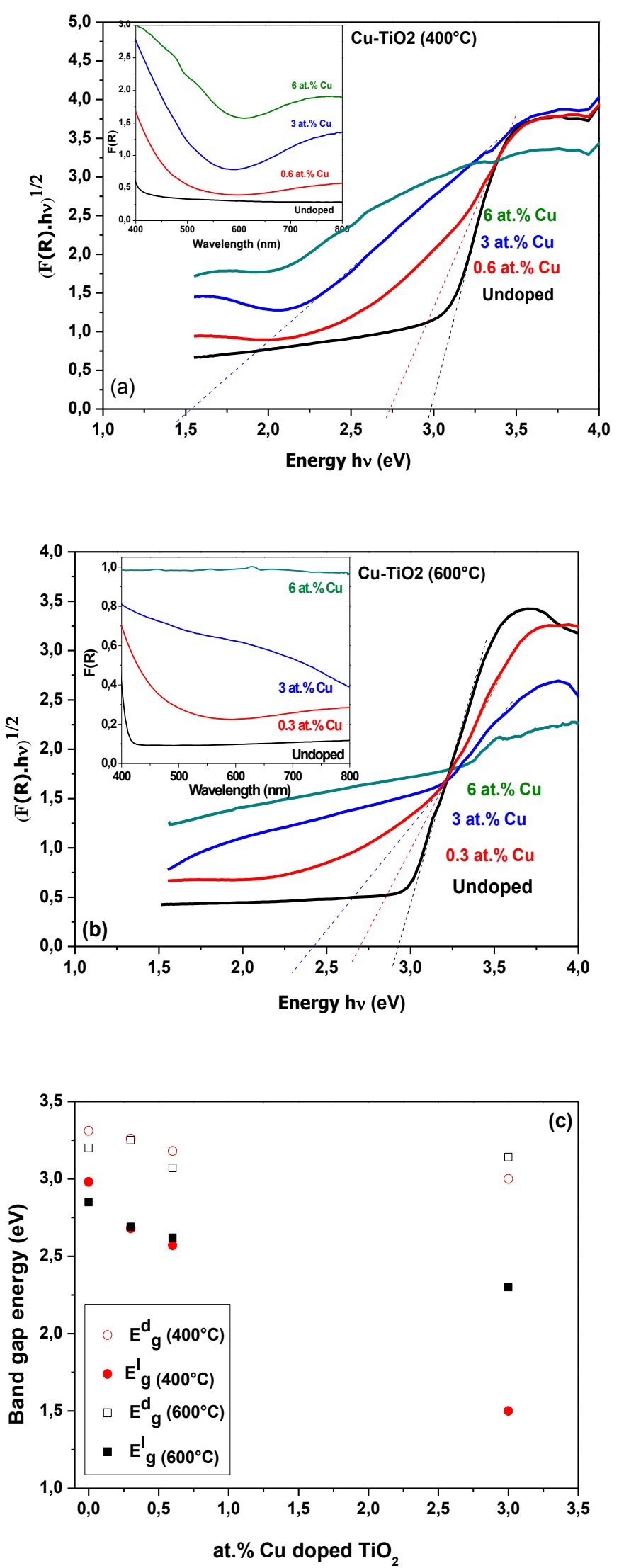
Fig.9
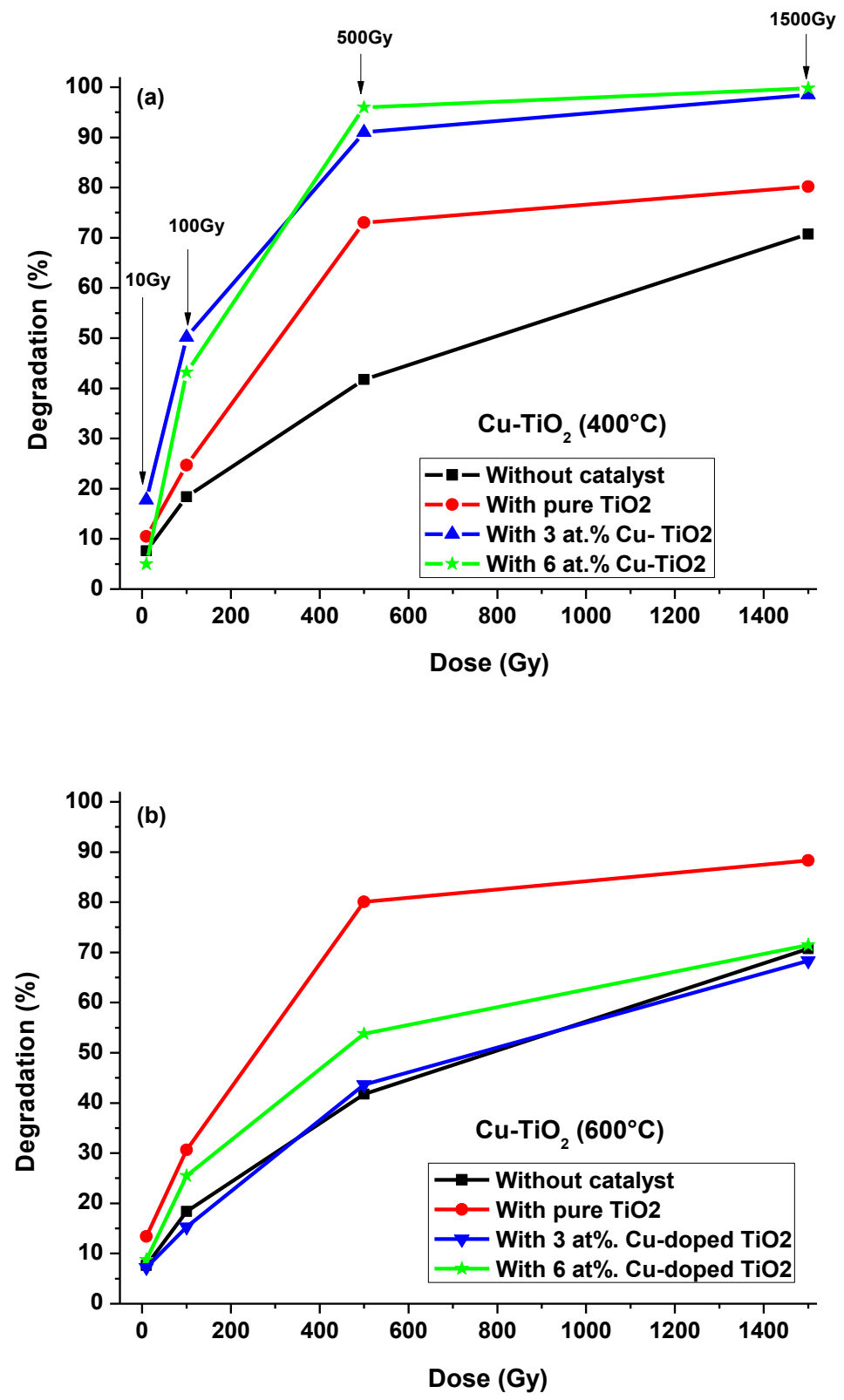